\title{
Gut Microbiota from Lower Groups of Animals: An Upcoming Source for Cellulolytic Enzymes with Industrial Potentials
}

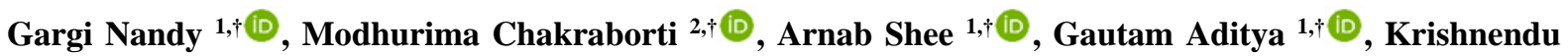 \\ Acharya ${ }^{2, *}$ (D) \\ 1 Department of Zoology, University of Calcutta, 35, Ballygunge Circular Road, Kolkata-700 019, India \\ 2 Molecular and Applied Mycology and Plant Pathology Laboratory, Centre of Advanced Study, Department of Botany, \\ University of Calcutta, 35, Ballygunge Circular Road, Kolkata-700 019, India \\ * Correspondence: krish_paper@yahoo.com; \\ $\dagger$ These authors contributed equally to this work.
}

Scopus Author ID 42761171800

Received: 15.12.2020; Revised: 28.01.2021; Accepted: 4.02.2021; Published: 11.02.2021

\begin{abstract}
Cellulosic plant materials are a reliable source of renewable energy. Cellulose-based plant materials are now being used for bioenergy production as alternatives to fossil fuels. The traditional way of converting lignocellulosic materials to ethanol and other bioenergy is an expensive and environmentally unsafe process. Several research works have been conducted to find outsource of lowcost cellulolytic enzymes. Initially, fungal species were considered as sources of cellulolytic enzymes. Later on, several studies showed that bacterial species are a more potent source of cellulose-degrading enzymes. Phytophagous lower invertebrates are a good source of cellulolytic gut bacteria. They utilize a wide variety of plant materials as their food source. In this review, thorough literature studies have been made to explore the invertebrate groups that are novel sources of cellulolytic gut bacteria with high efficacy for enzyme production. This study also encompasses a brief description of cellulose, the activity, and cellulase enzyme application in industrial aspects.
\end{abstract}

Keywords: renewable energy; cellulose; cellulase; lower invertebrates; cellulolytic gut bacteria; microorganisms.

(c) 2021 by the authors. This article is an open-access article distributed under the terms and conditions of the Creative Commons Attribution (CC BY) license (https://creativecommons.org/licenses/by/4.0/).

\section{Introduction}

Lignocellulosic biomass is the most abundant biological macromolecules in nature. It can be a promising source of renewable raw materials for the production of biofuels and various chemicals[1-12]. The plant cell wall comprises $35-50 \%$ cellulose and $20-35 \%$ hemicellulose with $5-30 \%$ lignin that together provides $90 \%$ of the dry weight of plant materials[2]. These huge amounts of biomasses are ultimately disposed of as waste materials in nature. But proper processing of these lignocellulosic wastes can mitigate the environmental and energetic demand for sustainable and renewable bioenergy [3,13-16]. Recent trends have adopted cellulosic raw materials over fossil fuels $[10,13,17,18]$ because of their several drawbacks. Brazil is the pioneered country in utilizing renewable energy and produces ethanol from sugarcane since the 1970s [13]. But the processing of these energy resources through instrument intensive, the thermochemical treatment process is very expensive [19] and needs an alternative one. The traditional way of converting lignocellulosic materials to ethanol requires acid-reliant hydrolysis and fermentation steps, which ended up with the formation of 
a large amount of calcium sulfate deposited as waste materials with some adverse effects on the environment [13]. The development of environmentally safe and economically feasible technologies for cellulase production is the key requirement for successfully utilizing plant biomass as a viable and foreseeable carbon source. Enzymatic degradation by cellulase or hemicellulase is the cost-effective way to saccharify cellulose and hemicellulose, respectively [20,21] to its monomer [22] hexose and pentose residues. Other hydrolytic enzymes such as pectinase, xylanase, and ligninase also ensure a high rate of degradation of the cellulose to its monomer and a high yield of biofuels lignocellulosic plant biomass [23]. The rate and efficacy of ethanol production from these monomers solely depend on the fermentation efficiency and enzymatic activity of microorganisms. These enzymes have potential application in food processing, winery, textile and laundry industry, paper and pulp preparation, animal feed, agricultural industry, and waste management process [1,24-28]. In bioethanol's industrial production, basic yeast Saccharomyces cerevisiae is used as it has some unique features, including high productivity of ethanol and alcohol tolerance [6,29-32]. But the activity of Saccharomyces cerevisiae gradually decreases due to byproduct inhibition and thus restricts its application for industrial use [33,34]. Thus identification and isolation of impeccable microorganisms with high production efficacy, high yield of several biofuels, and resistances to inhibitors are the necessary steps for industrial production of biofuels from cellulosic raw materials[30,35]. Initially, several cellulose digestive enzymes have been isolated from several fungal species, but they have some limitations, including low specific activity, low thermal stability, and narrow $\mathrm{pH}$ range tolerance. That is why several bacterial species are being explored later on for isolation and screening of cellulase production [2]. Herbivorous animals and wood-feeders cannot synthesize cellulase within their body but rely on their gut bacterial community [14], which possess a repertoire for cellulase synthesis [36]. Some cellulolytic bacteria strains have also been identified from environmental sources such as agricultural wastes, composts, woody wastes etc. [37-41]. Recently isolation and identification of gut microbiota from the phytophagous animals have gained momentum due to the diverse availability of several phytophagous insects, beetles, termites that thrive through several ecological niches and feed on several leafy and woody materials. In this review, an in-depth literature study has been conducted to enlist the lower invertebrates recognized so far to harbor cellulolytic bacterial populations within their gut. The lower invertebrates with endogenous cellulolytic systems are also discussed here - this review also encloses a brief description of cellulase and its mode of action. Furthermore, biotechnological approaches for improving its activity and application in several industrial aspects have also been discussed.

\section{Structure of Cellulose and Cellulase}

Cellulose is a fibrous, tough, and water-insoluble substance, which gives rigidity to plant cell walls and is found in stalks, stems, trunk, and all the woody portions of the plant body. It is a tasteless, odorless, and hydrophilic substance. It is a linear and unbranched homopolysaccharide made of D-glucose unit with the chemical formula $\left(\mathrm{C}_{6} \mathrm{H}_{12} \mathrm{O}_{6}\right)_{\mathrm{n}}$. The number of D-glucose units can range from 10,000 - 15,000. In cellulose, glucose residues are linked by $\beta$ 1-4 glycosidic bond.In nature, cellulose molecules exist in four crystalline forms (I $\alpha$, I $\beta$, II, and III), which vary in physiochemical properties. The crystalline structure of cellulose comprises several cellulose fiber chains, which are interlinked by hydrogen bonds between hydroxyl groups of adjacent molecules. These hydrogen bonds and Vander Wall 
forces together make robust and stable cellulose crystals. At ambient temperature, these hydrogen bonds of cellulose molecules can only be hydrolyzed by the cellulase enzyme system's synergistic action. Cellulase is a multienzyme system, which consists of three major components: 1, 4- $\beta$-endoglucanase (EC 3.2.1.4), 1,4- $\beta$-exoglucanase (EC 3.2.1.91) and $\beta$ glucosidase (EC.3.2.1.21) ( $\beta$-D-glucoside glucohydrolase or cellobiase) [42]. Endoglucanase causes random cleavage of $\beta$-1,4-glycosidic bonds along a cellulose chain, liberating a new end. Exoglucanase imparts an exo-attack at the reducing or non-reducing end of microcrystalline cellulose and produces glucose or cellobiose as the end product. $\beta$ glucosidase is responsible for cellobiose hydrolysis, producing glucose as the end product [43](Figure.1).The synergistic and sequential action of all these three enzymes facilitates the complete hydrolysis of cellulose to glucose.

Symbiotic microorganisms within the insect gut have a significant contributions to the nutritional ecology of insects [44]. The persistent association of microorganisms in the insect digestive tract provides nutritional advantage through several physiological activities, including digestion and detoxification of specific foodstuff, synthesis of essential amino acids, vitamins, sterol, and nitrogen fixation, and production of pheromone $[2,44,45]$. Woodborer and plant-eating insects cannot digest their foodstuffs easily as cellulosic plant materials are very stable polymer and require enzymatic attack for degradation [44]. Partial degradation during insect chewing makes some cellulose of foodstuffs available for cellulase enzyme. Endoglucanases or CMCases from different microbial sources consist of catalytic modules of glycosyl hydrolase families (GH) 5-9, 12, 44, 45, 48, 51, and 74. Bacterial endoglucanases possess multiple catalytic modules, carbohydrate-binding modules (CBMs), and other modules, while fungal endoglucanases possess a catalytic module with or without a CBM [43]. Most of the exoglucanases are cellobiohydrolases (CBHs), which are produced in different forms by bacteria and fungi. The catalytic modules of $\mathrm{CBHs}$ belong to the glycosyl hydrolase family of $5,6,7,9,48$, and $74[43]$.

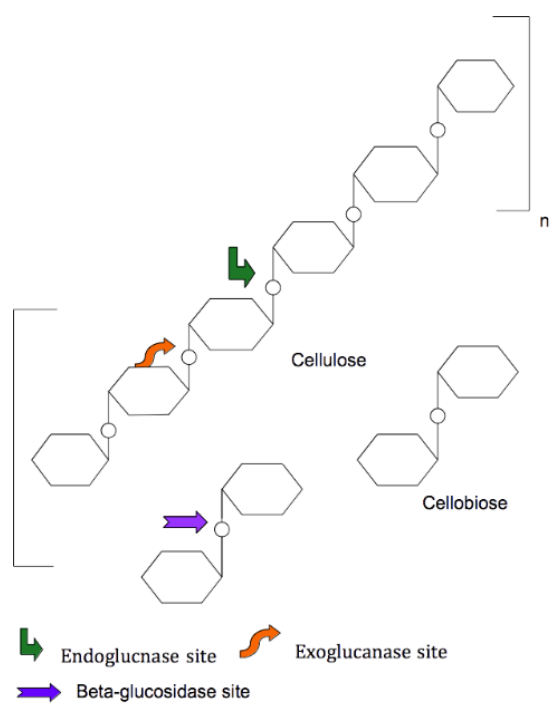

Figure 1. Cellulose hydrolysis: Activity site of endoglucnase, exoglucanase and beta-glucosidase on cellulose molecule.

The glycoside hydrolase family's exoglucanases 48 mainly act on crystalline cellulose and induce its hydrolysis, which is mediated by bacterial cellulase systems. $\beta$-glucosidase (BGs) does not possess CBM in catalytic modules and hydrolyze soluble cellodextrins and cellobiose to glucose. Cellobiose is an inhibitor of endoglucanase and CBH. Different 
microorganisms produce various BGs with catalytic modules belonging to families 1,3 , and 9.Generally, aerobic fungi produce BGs extracellularly, but BGs of anaerobic bacteria remain within their cytoplasm [43]. Microbial cellulase within the anaerobic insect gut is associated with the large enzyme integrating protein scaffoldin, which contains multiple copies of cohesin modules to integrate the different enzymes and other components. These entire components together form a multienzyme cellulosome complex [46]. Cellulase and other enzymes contain a complementary cohesin-docking domain that specifically binds to the cohesin modules of scaffoldin. Scaffoldin modules also have carbohydrate-binding domains that facilitate the cellulosome complex (Figure. 2) to bind with cellulosic substrates for degradation [46]. Cellulosome complex in association with several cellulases promotes the degradation of most recalcitrant cellulose molecules into monomeric glucose molecules utilized by insects and herbivorous animals as an energy source.

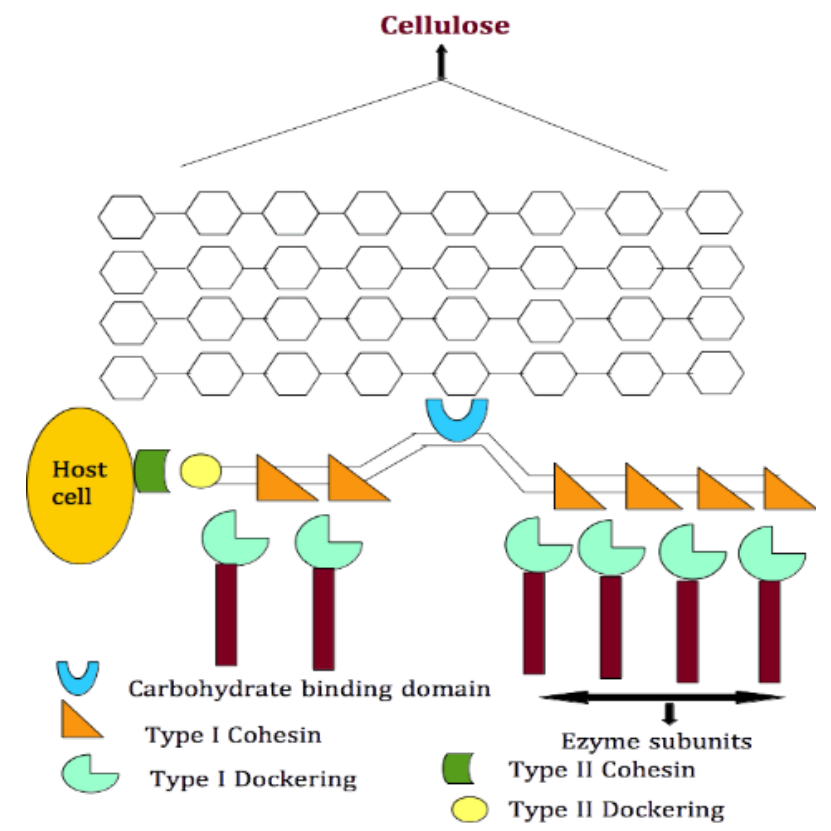

Figure 2. Mode of action of cellulase enzyme-Cellulosome structure.

\section{Sources of Cellulolytic Bacteria}

In recent years, an increasing trend in the search for newer sources of cellulosedegrading microorganisms is observed, keeping in view the diverse application of the cellulase in industrial sectors $[1,11,24-26,28,47,48]$. The fungus Trichoderma reesei was the most potential cellulase-producing microorganism [49] over the years. Nowadays, several studies have been aimed in search of newer microorganisms, including bacteria from several environmental sources, including municipal solid wastes [49], compost [37], agro-industrial wastes [7,35,38], soil [50-52], palm wastes (fiber and palm leaves), woody wastes, manure, straw and sugarcane molasses [53-55], mangrove soil sediment [56,57]. The aquatic environment such as moist peat and water of freshwater wetland reserve [58], lake sediments [59], water-sludge mixtures of hot-springs [16,60], and marine environment [61,62] also harbor a widespread spectrum of cellulose-degrading microorganisms.

Besides these environmental sources, many phytophagous lower invertebrates' gut microbiota has been empirically studied to obtain microorganisms with cellulolytic potential. Cellulase activity within the invertebrate digestive tract has been determined in the long past [63]. Literature reflects that the following invertebrate groups have been studied previously for cellulolytic gut bacterial source: 


\subsection{Arthropods-insects.}

Diversified habitat and plant fiber-based diet make Arthropods a potent reservoir of several gut microbial communities. Literature survey depicts that various Arthropoda species have been explored thoroughly in search of gut microbiota with cellulolytic potential $[2,64]$. Among Arthropods, insects are the most studied group regarding obtaining novel gut bacterial strain, which can synthesize cellulase enzyme with industrial potential $[20,44,65]$. Due to the wide range of diversity and multitrophic relationships between insect groups and plant hosts, insect species harbor symbiotic bacterial communities within their digestive tract $[44,66,67]$. Diverse ecological niches and the phytophagous nature of insects have raised interest in studying the digestion mechanism of insect species involving microbial and endogenous cellulase [20,68]. Insect group, termites have evolved with symbiotic systems [69] that efficiently degrade lignocellulosic foodstuffs [70,71,72] and thus make the termite group a promising source of cellulolytic enzymes. Termite consists of 2000 described species that are subdivided into two groups, namely 'higher' and 'lower' group [70,73,74]. Both groups are involved in symbiotic relationships with prokaryotes, but lower groups are also the protists' host $[70,73,74]$. As most of the termites are wood and soil dwellers, symbiotic relationships with protozoan and prokaryotic fauna within their gut help them turn over the complex biopolymer of wood and other cellulosic and lignocellulosic foodstuffs[73,75].Termites are more potent in cellulose degradation and assimilation than other cellulose utilizing invertebrates [69]. Termites are also found to utilize fungus derived cellulolytic enzyme by making an intriguing symbiotic relationship with fungal species [76]. Cellulolytic gut bacteria have been screened in many species of termites, including Zootermopsis angusticollis [75], Nasutitermes lujae [77], Macrotermes gilvus [78], Coptotermes gestroi [79], Cryptotermes sp.[80], Coptotermes formosanus [81], Coptotermes heimi [82], Cryptotermes brevis [83], Psammotermes hypostoma Desneux [84], Amitermes evuncifer [85], Macrotermes gilvus [86], Coptotermes curvignathus [87].

The gut of Scarabaeidae beetle larvae is considered a potent bioreactor for the conversion of lignocellulosic materials to biofuels [88]. Scarabaeids larvae are humivorous feeding on soil organic matter, decaying plant roots, and woods, which are digested by the enzyme-producing microorganisms inhabiting within their digestive tract. The cellulolytic bacterial community has been screened within the larval gut of several Scarabaeidae beetle larvae, including Pachnoda marginata [89], Holotrichia parallela [30,90], Oryctes rhinoceros [91-93], Lepidiota mansueta [94], Euoniticellus intermedius [95], Anamola dimidiata [96]. Apart from Scarabaeids, other insect larvae such as Dendroctonus armandi (Curculionidae) [97], Osphranteria coerulescens (Cerambycidae) [98], banana pseudostem weevil Odoiporus longicollis (Coleoptera) [99] are also the host of the cellulose-degrading gut microbiome. Cellulolytic bacteria of five genera have been isolated from the larval gut of the moth Diatraea saccharalis [100,101]. The larvae of silkworm Bombyx mori feed on mulberry leaves composed of pectin, xylan, cellulose, and starch. And thus,Bombyx mori larvae also depend on gut bacteria for their dietary cellulose degradation [102,103]. Honey bees (Apis mellifera) are also considered as model organisms for the study of saccharide digestive gut microbiota [104]. Worker honey bees produce honey and bee bread by processing nectar and pollen, respectively. The honey and bee bread production mechanism depends on saccharide digestive enzymes produced by the gut microbiome of honey bees [104]. Other insects like silver crickets Lepisma sp. [105], mole crickets Gryllotalpa africana [106], rice weevil Sitophilus oryzae [107], coffee 
berry borer Hypothenemus hampei [108], desert locust Schistocerca gregaria [109] also host gut microbes that degrade cellulosic foodstuffs.

Most of the termite species utilize microbial cellulase for degradation of the cellulosic foodstuffs, but the existence of endogenous cellulase has been reported within the gut of subterranean termite Reticulitermes speratus [110]. Apart from termite, endogenous cellulase activity has been found in other insect order also [19]. Most of the study has prioritized isolation and quantification of cellulolytic bacteria from different insect gut regions; some work has been focused on metagenomic and pyrosequencing approaches to identify cellulase-encoding genes. Termites are the insects in which cellulase genes have been first discovered [111], followed by other insect species belonging to the order Coleoptera [112,113], Hymenoptera [114], Orthoptera [115], and Hemiptera. $\beta$ - glucosidase and endo - $\beta$ - 1,4 glucanase activities have been estimated in the gut of Nasutitermes takasagoensis [116]. Moreover, through the metagenomic approach, 45 different glycoside hydrolases ( $\mathrm{GH}$ family) genes have been reported in higher termite Nasutitermes takasagoensis [117]. Researchers have identified endogenous cellulolytic systems within the beetle larvae also. With the aid of transcriptomic technology, one cellulase of glycoside hydrolase family 45 (GH45) and seven GH5 cellulases have been identified from the beetle larvae of Mesosa myops [118]. Two $\beta$-glycosidases ( $\beta$ Gly1 and $\beta$ Gly2) have been purified from the midgut lumen of beetle Tenebrio molitor larvae [119]. Endogenous cellulase activities have also been detected in the gut homogenate of several cockroach species $[64,120]$. Cellulose digesting activity has also been determined in the digestive fluids of some other insects, including grasshopper Dissosteira carolina [121] and Schistocerca gregaria [64], longhorn beetle Hylotrupes bajules, Crickets Acheata domesticus, Stick insects Eurycanta calcarata [64], and locusts species [122].

\subsection{Annelids.}

Soil and plant litter dwelling earthworms are also known to possess glucose degrading enzymatic machinery within their gut. Microbial assemblages within the earthworm gut and casts facilitate enzymatic processing and mineralization of organic polymer of soil and plant biomass [123]. Cellulose degrading microbial community has been isolated from several species of earthworm, which include Eudrilus eugeniae [124-126], Amynthas heteropoda [127], Eisenia fetida [127-129], Perionyx excavatus, and Glyphidrilus spelaeotes [130]. Earthworms also rely on dual digestive mechanisms involving both endogenous and microbial cellulase for lignocellulose degradation. Few reports demonstrate that earthworms possess complete enzymatic machinery for glycosidic enzymes [131-134]. Glycolytic activities in the gut have been detected in the earthworm species Pontoscolex corethrums[118], Millsonia anomala [132], Polypheretima elongata [133], Hormogaster elisae [134, 135], Hyperiodrilus africaizus, Dichogaster terrae nigrae [135], Pheretima hilgendorfi [136]. Nacetylglucosaminase, laminarinase, laminaribiase activities are found to be most potent within the gut of these earthworm species except Pheretima hilgendorfi. These enzymes induce degradation of $\beta-1,3$ glucan, and chitin sub-units, which are characteristic components of fungal cell walls [131,134]. Higher activities of these enzymes corroborate that these earthworm species feed on fungus and decaying root exudates. Week activities of other glycolytic enzymes within the gut of earthworms reflect their dependency on microbial cellulases for degradation of substrates like mannan and cellulose [134]. In the case of Pheretima hilgendorfi, endo- $\beta$-1, 4-glucanase contributes to the degradation of cellulose, and a novel cellulase gene (phhEg) has been detected from this species [136]. 


\subsection{Molluscs.}

Apart from insects, some empirical studies have also been conducted to determine cellulolytic bacteria in snail species. Land snails (Gastropoda: Pulmonata) include several distinct lineages of terrestrial gastropods, which utilize various resources of the terrestrial ecosystem that make them efficient in exploiting the available niches, which is why the realized diversity is quite high. They are generally herbivorous, feed upon a wide range of plant materials, and many of them are the pests of agricultural and horticultural plants [137]. As most land snail species consume cellulosic and lignocellulosic materials, they can be a viable and potential source of cellulolytic gut microbe fauna. Pioneered study on bacterial cellulase in the animal gut has been conducted on land snail Helix pomatia [138,139], which has been followed by Florkin and Lozet 1949 [140]and Jeuniaux 1950, 1955 [141,142], who worked on the contribution of microbial cellulase and chitinase respectively in the degradation of plant material in the gut of $H$. pomatia. The African giant snail Achatina fulica (MolluscaGastropoda)is the most studied snail species in this respect. The existence of endogenous cellulase within the gut of A. fulica is evident from the work of Soedigdo et al. 1970 [143] and Dar et al. 2020 [144]. Microbial communities with cellulolytic potential have been isolated from Achatina fulica [7,145-147] and Arachatina marginata[148,149]. Few works have been aimed to investigate the physiochemical environment of the gut of helicid snails[150], the occurrence of fermentative bacteria in edible snail Helix pomatia and Cornu aspersum (Gastropoda: Pulmonata) [151], and homolactic intestinal bacteria of Helix aspersa [152], but the detailed works emphasizing microbial contribution in the digestion of cellulose biopolymer in several other gastropod snail guts are yet to be deciphered. Other molluscan species such as marine turban shell Batillus cornutus has been found to possess polysaccharide digesting gut bacteria [153] and wood-boring bivalvia Bankia setacea also depends on nitrogen-fixing cellulolytic endosymbionts for wood degradation in the marine environment [154-157]. The cellulolytic activity within the different areas of the gut of the land slug Arionater had been detected through the CMC zymography and esculin hydrate activity gel assays, which revealed the existence of endoglucanase and $\beta$-glucosidase enzymes [158] within their gut. Further study was carried out to isolate and identify cellulolytic bacterial colony within the Ariongut, which was the main source of enzyme activity within the gut [158]. Four endo- $\beta-1,4-$ glucanases $(21 \mathrm{~K}, 45 \mathrm{~K}, 65 \mathrm{~K}$, and $95 \mathrm{~K}$ cellulase) and $2 \beta$-glucosidases $(110 \mathrm{~K}$ and $210 \mathrm{~K}$ ) were purified from the digestive fluid of sea hare Aplysia kurodai [159]. These enzymes were able to hydrolyze CMC, filter papers, and lichenan, and these all cellulase were able to digest seaweeds, mainly sea lettuce Undaria pinnatifida [159].

Literature survey reflects that insect species are prioritized for the investigation of the gut bacterial community. Other phytophagous species such as terrestrial snails or algae or seaweed consuming aquatic snails and geophagous earthworms can also be efficient model species. Exploration of more invertebrate species may be helpful for the discovery of novel microorganisms with cellulolytic potentials. Lists of lower invertebrates and their gut bacterial strains with cellulolytic potentials (Table 1) and the specific activity of gut bacterial cellulolytic enzymes (Table 2) are presented in this review.

\section{Biotenchnology and Industrial Application of Cellulase}

Biotechnological approaches have been adopted in the long past since the 1980s to apply cellulase in the food industry, followed by several other commercial and industrial parts 


\section{[1]. Commercially available cellulolytic enzymes are usually extracted from Trichoderma reesei and Aspergillus niger [1].}

Table 1. List of several lower invertebrate species that host gut microbes with cellulolytic potential.

\begin{tabular}{|c|c|c|c|c|}
\hline Species name & Systematic position & Bacterial strains identified & $\begin{array}{l}\text { Cellulolytic enzyme activity of } \\
\text { the culture Supernatant of the } \\
\text { isolated bacterial strains }\end{array}$ & Reference \\
\hline $\begin{array}{l}\text { Termite } \\
\text { (Odontotermes } \\
\text { hiananensis), pill- } \\
\text { bugs (Armadillidium } \\
\text { sp), yellow stem } \\
\text { borers (Scirpophaga } \\
\text { incertulas) }\end{array}$ & $\begin{array}{l}\text { Arthropoda-Insecta- } \\
\text { Blattodea-Termitidae: } \\
\text { Odontotermes } \\
\text { hiananensis, } \\
\text { Arthropoda-Crustacea- } \\
\text { Malacostraca-Isopoda: } \\
\text { Armadillidium sp., } \\
\text { Arthropoda-Insecta- } \\
\text { Lepidoptera-Crambidae: } \\
\text { Scirpophaga incertulas }\end{array}$ & $\begin{array}{l}\text { Bacterial families isolated } \\
\text { belong to Bacillaceae, } \\
\text { Enterobacteriaceae, } \\
\text { Microbacteriaceae, } \\
\text { Paenibacillaceae and } \\
\text { Promicromonosporaceae }\end{array}$ & $\begin{array}{l}\text { endoglucanase, exoglucanase, } \beta- \\
\text { glucosidase, xylanase, b- } \\
\text { xylosidase, mannanase and b-D- } \\
\text { glucanase. }\end{array}$ & [2] \\
\hline $\begin{array}{l}\text { Termite } \\
\text { (Zootermopsis } \\
\text { angusticollis) }\end{array}$ & $\begin{array}{l}\text { Arthropoda-Insecta- } \\
\text { Blattodea-Termopsidae }\end{array}$ & $\begin{array}{l}\text { Among several isolates, } \\
\text { Cellulomonas sp., Bacillus (e.g. } \\
\text { B. cereus and B. megaterium), } \\
\text { and Paenibacillus sp. were with } \\
\text { highest CMC degrading } \\
\text { capability }\end{array}$ & $\begin{array}{l}\text { enzyme assay was not } \\
\text { performed, } \\
\text { Cellulolytic bacterial strains } \\
\text { were isolated based on the clear } \\
\text { zone diameter of degraded CMC } \\
\text { area around the colony in plate } \\
\text { assay method. }\end{array}$ & [75] \\
\hline $\begin{array}{l}\text { Wood-feeding } \\
\text { Termite, Nasutitermes } \\
\text { lujae }\end{array}$ & $\begin{array}{l}\text { Arthropoda-Insecta- } \\
\text { Blattodea-Termitidae }\end{array}$ & Clostridium termitidis $\mathrm{sp}$. & \begin{tabular}{|l|} 
enzyme assay was not \\
performed, \\
Cellulolytic bacterial strains \\
were isolated based on the clear \\
zone diameter of degraded CMC \\
area around the colony in the \\
plate assay method.
\end{tabular} & [77] \\
\hline $\begin{array}{l}\text { Termite worker } \\
\text { Macrotermes gilvus }\end{array}$ & $\begin{array}{l}\text { Arthropoda-Insecta- } \\
\text { Blattodea-Termitidae }\end{array}$ & $\begin{array}{l}\text { Bacillus megaterium and } \\
\text { Paracoccus yeei }\end{array}$ & $\begin{array}{l}\text { enzyme assay was not } \\
\text { performed, } \\
\text { Cellulolytic bacterial strains } \\
\text { were isolated based on the clear } \\
\text { zone diameter of degraded CMC } \\
\text { area around the colony in the } \\
\text { plate assay method. }\end{array}$ & [78] \\
\hline $\begin{array}{l}\text { Milk termite } \\
\text { (Coptotermes gestroi) }\end{array}$ & $\begin{array}{l}\text { Arthropoda-Insecta- } \\
\text { Blattodea-Rhinotermitidae }\end{array}$ & $\begin{array}{l}\text { Bacillus sp., } \\
\text { Enterobacter sp., } \\
\text { Bacillus megaterium, } \\
\text { Pseudomonas aeruginosa and } \\
\text { Bacillus cereus }\end{array}$ & $\begin{array}{l}\text { enzyme assay was not } \\
\text { performed, } \\
\text { Cellulolytic bacterial strains } \\
\text { were isolated based on the clear } \\
\text { zone diameter of degraded CMC } \\
\text { area around the colony in the } \\
\text { plate assay method. }\end{array}$ & [79] \\
\hline Cryptotermes sp. & \begin{tabular}{|l|} 
Arthropoda-Insecta- \\
Blattodea-Rhinotermitidae
\end{tabular} & $\begin{array}{l}\text { Three isolates of genus } \\
\text { Clostridium, one isolate of group } \\
\text { Mycobacteriaceae, } \\
\text { Lactobacillaceae or Coryneform, } \\
\text { and the last one in the genus } \\
\text { Proteus }\end{array}$ & $\begin{array}{l}\text { enzyme assay was not } \\
\text { performed, } \\
\text { Cellulolytic enzyme activities } \\
\text { had been screened based on the } \\
\text { clear zone diameter of degraded } \\
\text { CMC area around the colony in } \\
\text { the plate assay method. }\end{array}$ & [80] \\
\hline $\begin{array}{l}\text { Termite Coptotermes } \\
\text { formosanus }\end{array}$ & \begin{tabular}{|l|} 
Arthropoda-Insecta- \\
Blattodea-Rhinotermitidae
\end{tabular} & $\begin{array}{l}\text { Pseudomonas mendocina, } \\
\text { Burkholderia pseudomallei, } \\
\text { Chryseobacterium luteola, } \\
\text { Klebsiella oxytoca and } \\
\text { Klebsiella terrigena }\end{array}$ & $\begin{array}{l}\text { filter paperase } \\
\text { (The cellulolytic enzyme activity } \\
\text { of the microbe was examined in } \\
\text { a broth culture using filter paper } \\
\text { as carbon source) }\end{array}$ & [81] \\
\hline $\begin{array}{l}\text { Termite Coptotermes } \\
\text { heimi }\end{array}$ & \begin{tabular}{|l|} 
Arthropoda-Insecta- \\
Blattodea-Rhinotermitidae
\end{tabular} & $\begin{array}{l}\text { Bacillus sp., } \\
\text { Proteus sp., } \\
\text { Ochrobactrum sp., } \\
\text { Erwinia sp., } \\
\text { Aeromonas sp. and } \\
\text { Citrobacter sp. }\end{array}$ & $\begin{array}{l}\text { enzyme assay was not } \\
\text { performed, } \\
\text { Cellulolytic enzyme activities } \\
\text { had been screened based on the } \\
\text { clear zone diameter of degraded } \\
\text { CMC area around the colony in } \\
\text { the plate assay method. }\end{array}$ & [82] \\
\hline $\begin{array}{l}\text { Termite Cryptotermes } \\
\text { brevis }\end{array}$ & $\begin{array}{l}\text { Arthropoda-Insecta- } \\
\text { Blattodea-Kalotermitidae }\end{array}$ & $\begin{array}{l}\text { Bacillus sp. and Ochrobactrum } \\
\text { oryzae }\end{array}$ & $\begin{array}{l}\text { xylanase, CMCase, lignin } \\
\text { peroxidase, laccase }\end{array}$ & 83] \\
\hline
\end{tabular}




\begin{tabular}{|c|c|c|c|c|}
\hline Species name & Systematic position & Bacterial strains identified & $\begin{array}{l}\text { Cellulolytic enzyme activity of } \\
\text { the culture Supernatant of the } \\
\text { isolated bacterial strains }\end{array}$ & Reference \\
\hline $\begin{array}{l}\text { Termite } \\
\text { Psammotermes } \\
\text { hypostoma Desneux }\end{array}$ & $\begin{array}{l}\text { Arthropoda-Insecta- } \\
\text { Blattodea-Rhinotermitidae }\end{array}$ & $\begin{array}{l}\text { Paenibacillus lactis, } \\
\text { Lysinibacillus macrolides, } \\
\text { Stenotrophomonas maltophilia, } \\
\text { Lysinibacillus fusiformis and } \\
\text { Bacillus cereus }\end{array}$ & cellulase (endoglucanase) & [84] \\
\hline $\begin{array}{l}\text { Termite Amitermes } \\
\text { evuncifer }\end{array}$ & $\begin{array}{l}\text { Arthropoda-Insecta- } \\
\text { Blattodea-Termitidae }\end{array}$ & \begin{tabular}{|l} 
Bacillus cereus, \\
Bacillus mycoidesand \\
Pseudomonas aeruginosa
\end{tabular} & $\begin{array}{l}\text { endoglucanase (CMCase) and } \\
\text { exoglucanase (FPase) and }\end{array}$ & [85] \\
\hline $\begin{array}{l}\text { Termite Macrotermes } \\
\text { gilvus }\end{array}$ & $\begin{array}{l}\text { Arthropoda-Insecta- } \\
\text { Blattodea-Termitidae }\end{array}$ & Provedencia sp., Bacillus sp. & $\begin{array}{l}\text { cellulase (on newsprint paper } \\
\text { substrate) }\end{array}$ & [86] \\
\hline $\begin{array}{l}\text { Termite Coptotermes } \\
\text { curvignathus }\end{array}$ & $\begin{array}{l}\text { Arthropoda-Insecta- } \\
\text { Blattodea-Termitidae }\end{array}$ & $\begin{array}{l}\text { Bacterial strains isolated were } \\
\text { mainly Bacillus spp. }\end{array}$ & $\begin{array}{l}\text { enzyme assay was not } \\
\text { performed, } \\
\text { Cellulolytic enzyme activities } \\
\text { had been screened based on the } \\
\text { clear zone diameter of degraded } \\
\text { CMC area around the colony in } \\
\text { the plate assay method }\end{array}$ & [87] \\
\hline Termite & Arthropoda-Insecta & $\begin{array}{l}\text { Dipolcocci sp., } \\
\text { Diplobacilli sp., } \\
\text { Streptobacilli sp. and } \\
\text { Staphylococci sp. }\end{array}$ & $\begin{array}{l}\text { enzyme assay was not } \\
\text { performed, } \\
\text { Cellulolytic enzyme activities } \\
\text { had been screened based on the } \\
\text { clear zone diameter of degraded } \\
\text { CMC area around the colony in } \\
\text { the plate assay method. }\end{array}$ & [160] \\
\hline $\begin{array}{l}\text { Holotrichia parallela } \\
\text { larvae }\end{array}$ & $\begin{array}{l}\text { Arthropoda-Insecta- } \\
\text { Coleoptera-Scarabaeidae }\end{array}$ & $\begin{array}{l}\text { Among many isolates } \\
\text { Siphonobacter aqua } \\
\text { eclarae, Cellulosi microbium } \\
\text { funkei, Paracoccus } \\
\text { sulfuroxidans, Ochrobactrum } \\
\text { cytisi, Ochrobactrum } \\
\text { haematophilum, Kaistia adipata, } \\
\text { Devosia riboflavina, } \\
\text { Labrys neptuniae, } \\
\text { Ensifer adhaerens, } \\
\text { Shinella zoogloeoides, } \\
\text { Citrobacter freundii and } \\
\text { Pseudomonas nitroreducens } \\
\text { were reported for the first time } \\
\text { as cellulolytic bacteria }\end{array}$ & $\begin{array}{l}\text { enzyme assay was not } \\
\text { performed, } \\
\text { Cellulolytic bacterial strains } \\
\text { were isolated based on the clear } \\
\text { zone diameter of degraded CMC } \\
\text { area around the colony in the } \\
\text { plate assay method. }\end{array}$ & [30] \\
\hline $\begin{array}{l}\text { Long horn beetle } \\
\text { Hylotrupes bajules }\end{array}$ & $\begin{array}{l}\text { Arthropoda-Insecta- } \\
\text { Coleoptera-Cerambycidae }\end{array}$ & Not identified & $\begin{array}{l}\beta \text {-glycosidase, CMC-ase, } \\
\text { xylanase }\end{array}$ & [64] \\
\hline $\begin{array}{l}\text { Larvae of the scarab } \\
\text { beetle Pachnoda } \\
\text { marginata }\end{array}$ & $\begin{array}{l}\text { Arthropoda-Insecta- } \\
\text { Coleoptera-Scarabaeidae }\end{array}$ & $\begin{array}{l}\text { Promicromonospora pachnodae } \\
s p .\end{array}$ & CMC-ase and xylanase & [89] \\
\hline $\begin{array}{l}\text { Holotrichia parallela } \\
\text { larvae }\end{array}$ & $\begin{array}{l}\text { Arthropoda-Insecta- } \\
\text { Coleoptera-Scarabaeidae }\end{array}$ & Pseudomonas sp. & endoglucanase & [90] \\
\hline $\begin{array}{l}\text { Larvae of Oryctes } \\
\text { rhinoceros }\end{array}$ & $\begin{array}{l}\text { Arthropoda-Insecta- } \\
\text { Coleoptera-Scarabaeidae }\end{array}$ & Genus Bacillus and Citroibacter & $\begin{array}{l}\text { enzyme assay was not } \\
\text { performed. } \\
\text { Cellulolytic, Xylanolytic, and } \\
\text { Mannanolytic enzyme activities } \\
\text { had been screened based on the } \\
\text { clear zone diameter of degraded } \\
\text { CMC area around the colony in } \\
\text { the plate assay method. }\end{array}$ & [91] \\
\hline $\begin{array}{l}\text { Larvae of Oryctes } \\
\text { rhinoceros }\end{array}$ & $\begin{array}{l}\text { Arthropoda-Insecta- } \\
\text { Coleoptera-Scarabaeidae }\end{array}$ & $\begin{array}{l}\text { Bacillus sp., } \\
\text { Proteus sp., } \\
\text { Ochrobactrum sp., } \\
\text { Erwinia sp., } \\
\text { Aeromonas sp., } \\
\text { Citrobacter sp. and } \\
\text { Pseudomonas sp. }\end{array}$ & $\begin{array}{l}\text { enzyme assay was not } \\
\text { performed, } \\
\text { Cellulolytic and ligninolytic } \\
\text { enzyme activities had been } \\
\text { screened based on the clear zone } \\
\text { diameter area around the colony } \\
\text { in the plate assay method. }\end{array}$ & [92] \\
\hline $\begin{array}{l}\text { Larvae of grub beetle } \\
\text { Lepidiota mansueta }\end{array}$ & $\begin{array}{l}\text { Arthropoda-Insecta- } \\
\text { Coleoptera-Scarabaeidae }\end{array}$ & Citrobacter sp. & $\begin{array}{l}\text { enzyme assay was not } \\
\text { performed, } \\
\text { Cellulolytic bacterial strains } \\
\text { were isolated based on the clear }\end{array}$ & [94] \\
\hline
\end{tabular}




\begin{tabular}{|c|c|c|c|c|}
\hline Species name & Systematic position & Bacterial strains identified & $\begin{array}{l}\text { Cellulolytic enzyme activity of } \\
\text { the culture Supernatant of the } \\
\text { isolated bacterial strains }\end{array}$ & Reference \\
\hline & & & $\begin{array}{l}\text { zone diameter of degraded CMC } \\
\text { area around the colony in the } \\
\text { plate assay method. }\end{array}$ & \\
\hline $\begin{array}{l}\text { Dung beetle } \\
\text { Euoniticellus } \\
\text { intermedius }\end{array}$ & \begin{tabular}{|l|} 
Arthropoda-Insecta- \\
Coleoptera-Scarabaeidae
\end{tabular} & Not identified & $\begin{array}{l}\text { enzyme assay was not } \\
\text { performed, } \\
\text { Cellulolytic bacterial strains } \\
\text { were isolated based on the clear } \\
\text { zone diameter of degraded CMC } \\
\text { area around the colony in the } \\
\text { plate assay method. }\end{array}$ & [95] \\
\hline $\begin{array}{l}\text { Larvae of Anamola } \\
\text { dimidiata }\end{array}$ & $\begin{array}{l}\text { Arthropoda-Insecta- } \\
\text { Coleoptera-Scarabaeidae }\end{array}$ & $\begin{array}{l}\text { The majority of the isolated } \\
\text { strain belonged to Firmicutes } \\
\text { and Proteobacteria }\end{array}$ & $\begin{array}{l}\text { endoglucanase, exoglucanase, } \beta \text { - } \\
\text { glucosidase }\end{array}$ & [96] \\
\hline $\begin{array}{l}\text { Larvae of } \\
\text { Dendroctonus } \\
\text { armandi }\end{array}$ & \begin{tabular}{|l|} 
Arthropoda-Insecta- \\
Coleoptera-Curculionidae- \\
Scolytinae
\end{tabular} & $\begin{array}{l}\text { Serratia sp., } \\
\text { Pseudomonas sp., } \\
\text { Bacillus sp., } \\
\text { Paenibacillus sp., } \\
\text { Sphingomonas, } \\
\text { Brevundimonasn, sp., } \\
\text { kwangchunensis sp., } \\
\text { Brevundimonas vesicularis, } \\
\text { Pseudoxanthomonas mexicana } \\
\text { and Methylobacterium populi }\end{array}$ & \begin{tabular}{|l|} 
enzyme assay was not \\
performed, \\
Cellulolytic bacterial strains \\
were isolated based on the clear \\
zone diameter of degraded CMC \\
area around the colony in the \\
plate assay method.
\end{tabular} & [97] \\
\hline $\begin{array}{l}\text { Larvae of } \\
\text { Osphranteria } \\
\text { coerulescens } \\
\end{array}$ & $\begin{array}{l}\text { Arthropoda-Insecta- } \\
\text { Coleoptera-Cerambycidae }\end{array}$ & Bacillus sp. & CMC-ase & [98] \\
\hline $\begin{array}{l}\text { Banana pseudostem } \\
\text { weevil Odoiporus } \\
\text { longicollis }\end{array}$ & \begin{tabular}{|l|} 
Arthropoda-Insecta- \\
Coleoptera-Curculionidae
\end{tabular} & Not identified & CMCase & [99] \\
\hline $\begin{array}{l}\text { Larvae of moth } \\
\text { Diatraea saccharalis }\end{array}$ & $\begin{array}{l}\text { Arthropoda- Insecta- } \\
\text { Lepidoptera-Crambidae }\end{array}$ & $\begin{array}{l}\text { Klebsiella oxytoca, } \\
\text { Klebsiella pneumonia, } \\
\text { Klebsiella variicola, } \\
\text { Stenotrophomonas maltophilia, } \\
\text { Stenotrophomonas rhizophila, } \\
\text { Bacillus pumilus, } \\
\text { Enterococcus casseliflavus, } \\
\text { Microbacterium hominis and } \\
\text { Microbacterium schleiferi, }\end{array}$ & CMC-ase & [100] \\
\hline $\begin{array}{l}\text { Larvae of moth } \\
\text { Diatraea saccharalis }\end{array}$ & $\begin{array}{l}\text { Arthropoda-Insecta- } \\
\text { Lepidoptera-Crambidae }\end{array}$ & $\begin{array}{l}\text { Klebsiella pneumoniae, } \\
\text { Klebsiella } \text { sp. and } \\
\text { Bacillus } \text { sp. }\end{array}$ & CMC-ase & [101] \\
\hline $\begin{array}{l}\text { Larvae of Bombyx } \\
\text { mori }\end{array}$ & $\begin{array}{l}\text { Arthropoda-Insecta- } \\
\text { Lepidoptera-Bombycidae }\end{array}$ & \begin{tabular}{|l|} 
Bacillus circulans, \\
Proteus vulgaris, \\
Klebsiella pneumonia, \\
Enterobacter sp., \\
Citrobacter freundii and \\
Serratia liquefaciens \\
\end{tabular} & $\begin{array}{l}\text { cellulase, xylanase, amylase, } \\
\text { pectinase }\end{array}$ & [102] \\
\hline Bombyx mori & \begin{tabular}{|l|} 
Arthropoda-Insecta- \\
Lepodoptera-Bombycidae
\end{tabular} & $\begin{array}{l}\text { Solibacillus silvestris, } \\
\text { Bacillus aryabhattai, } \\
\text { Lysinibacillus sp., } \\
\text { Bacillus sp., } \\
\text { Bacillus thuringiensis, } \\
\text { Paenibacillus sp., } \\
\text { Serratia marcescens, } \\
\text { Klebsiella pneumonia } \text { and } \\
\text { Enterobacter hormaechei } \\
\end{array}$ & CMC-ase & [103] \\
\hline $\begin{array}{l}\text { Silver cricket } \\
\text { Lepisma sp. }\end{array}$ & $\begin{array}{l}\text { Arthropoda-Insecta- } \\
\text { Zygentoma-Lepismatidae }\end{array}$ & Not identified & $\begin{array}{l}\text { filter paperase } \\
\text { (The cellulolytic enzyme activity } \\
\text { of the microbe was examined in } \\
\text { a broth culture using Whatman } \\
42 \text { filter as carbon source) }\end{array}$ & [105] \\
\hline $\begin{array}{l}\text { Mole crickets } \\
\text { Gryllotalpa africana }\end{array}$ & $\begin{array}{l}\text { Arthropoda-Insecta- } \\
\text { Orthoptera-Gryllotalpidae }\end{array}$ & Acinetobacter junii & CMC-ase & [106] \\
\hline $\begin{array}{l}\text { Rice weevil Sitophilus } \\
\text { oryzae }\end{array}$ & \begin{tabular}{|l|} 
Arthropoda-Insecta- \\
Coleoptera-Curculionidae
\end{tabular} & $\begin{array}{l}\text { Bacterial strains isolated belong } \\
\text { to Bacillus and } \gamma \text {-Protobacteria }\end{array}$ & sendoglucanase (CMCase) & [107] \\
\hline
\end{tabular}




\begin{tabular}{|c|c|c|c|c|}
\hline Species name & Systematic position & Bacterial strains identified & $\begin{array}{l}\text { Cellulolytic enzyme activity of } \\
\text { the culture Supernatant of the } \\
\text { isolated bacterial strains }\end{array}$ & Reference \\
\hline $\begin{array}{l}\text { Coffee berry borer } \\
\text { Hypothenemus } \\
\text { hampei }\end{array}$ & $\begin{array}{l}\text { Arthropoda-Insecta- } \\
\text { Coleoptera-Curculionidae }\end{array}$ & $\begin{array}{l}\text { Based on morphological and } \\
\text { biochemical characteristics, } \\
\text { isolated strain was similar to } \\
\text { genus Brochothrix }\end{array}$ & cellulase (CMCase) & [108] \\
\hline $\begin{array}{l}\text { Desert locust } \\
\text { Schistocerca gregaria }\end{array}$ & $\begin{array}{l}\text { Arthropoda-Insecta- } \\
\text { Orthoptera-Acrididae }\end{array}$ & Bacillus safensis & $\begin{array}{l}\text { enzyme assay was not } \\
\text { performed, } \\
\text { Cellulolytic bacterial strains } \\
\text { were isolated based on the clear } \\
\text { zone diameter of degraded CMC } \\
\text { area around the colony in the } \\
\text { plate assay method. }\end{array}$ & [109] \\
\hline $\begin{array}{l}\text { Termite, caterpillar, } \\
\text { bookworm and snail }\end{array}$ & $\begin{array}{l}\text { Arthropoda-Insecta } \\
\text { (termite, caterpillar, } \\
\text { bookworm) and Mollusca } \\
\text { (snail) }\end{array}$ & Not identified & $\begin{array}{l}\text { filter paperase and } \\
\text { endoglucanase }\end{array}$ & [161] \\
\hline $\begin{array}{l}\text { Oxya velox, } \\
\text { Aspidimorpha miliaris } \\
\text { and Propylea } \\
\text { quatuordecimpunctata }\end{array}$ & $\begin{array}{l}\text { Arthropoda-Insecta- } \\
\text { Orthoptera-Acrididae: } \\
\text { Oxya velox, } \\
\text { Arthropoda-Insecta- } \\
\text { Coleoptera- } \\
\text { Chrysomelidae: } \\
\text { Aspidimorpha miliaris, } \\
\text { Arthropoda-Insecta- } \\
\text { Coleoptera- Coccinellidae: } \\
\text { Propylea } \\
\text { quatuordecimpunctata }\end{array}$ & $\begin{array}{l}\text { Bacterial species isolated from } \\
\text { O. velox were Photorhabdus } \\
\text { luminescens, Enterococcus } \\
\text { faecalis, Enterococcus durans, } \\
\text { Flavobacterium odoratum, } \\
\text { Serretia marcescens and } \\
\text { Serretia entomophila. } \\
\text { Isolates identified from P. } \\
\text { quatuordecimpunctata } \text { were } \\
\text { Erwinia ananus, Aeromonas } \\
\text { salmonicida, Enterococcus } \\
\text { casseliflavus and Acinetobacter } \\
\text { calcoaceticus } \\
\text { Isolates identified from A. } \\
\text { miliaris } \text { were Klebsiella } \\
\text { oxytoca,Microbacterium } \\
\text { imperiale, Yersinia pestis, } \\
\text { Xenorhabdus poinari and } \\
\text { Pseudomonas saccharophila }\end{array}$ & $\begin{array}{l}\text { enzyme assay was not } \\
\text { performed, } \\
\text { Cellulolytic bacterial strains } \\
\text { were isolated based on the clear } \\
\text { zone diameter of degraded CMC } \\
\text { area around the colony in the } \\
\text { plate assay method. }\end{array}$ & {$[162]$} \\
\hline $\begin{array}{l}\text { Endogeic earthworms, } \\
\text { Amynthas heteropoda } \\
\text { and Eisenia fetida }\end{array}$ & $\begin{array}{l}\text { Annelida-Clitellata- } \\
\text { Haplotaxida- } \\
\text { Megascolecidae: } \\
\text { Amynthas heteropoda, } \\
\text { Annelida-Clitellata- } \\
\text { Haplotaxida-Lumbricidae: } \\
\text { Eisenia fetida }\end{array}$ & $\begin{array}{l}\text { Dominant bacterial and fungal } \\
\text { genus was Burkholderia and } \\
\text { Chaetomium respectively }\end{array}$ & $\begin{array}{l}\text { exoglucanase, endoglucanase, } \\
\text { xylanase, laccase }\end{array}$ & {$[123]$} \\
\hline $\begin{array}{l}\text { Earthworms Eudrilus } \\
\text { eugeniae }\end{array}$ & $\begin{array}{l}\text { Annelida-Clitellata- } \\
\text { Haplotaxida-Eudrilidae }\end{array}$ & Bacillus pumilus & endoglucanase & {$[124]$} \\
\hline $\begin{array}{l}\text { Earthworm Eudrillus } \\
\text { eugeniae }\end{array}$ & $\begin{array}{l}\text { Annelida-Clitellata- } \\
\text { Haplotaxida-Eudrilidae }\end{array}$ & Bacilus sp. & $\begin{array}{l}\text { amylase, nitrate reductase, } \\
\text { cellulase, xylnase, and protease }\end{array}$ & {$[125]$} \\
\hline $\begin{array}{l}\text { Earthworm Eisenia } \\
\text { foetida }\end{array}$ & $\begin{array}{l}\text { Annelida-Clitellata- } \\
\text { Haplotaxida-Lumbricidae }\end{array}$ & Lysinibacillus sphaericus & filter paperase & {$[128]$} \\
\hline $\begin{array}{l}\text { Earthworm Eisenia } \\
\text { fetida }\end{array}$ & $\begin{array}{l}\text { Annelida-Clitellata- } \\
\text { Haplotaxida-Lumbricidae }\end{array}$ & $\begin{array}{l}\text { Colony of Streptococcus, } \\
\text { Staphylococcus and Diplococcus }\end{array}$ & CMC -ase & [129] \\
\hline $\begin{array}{l}\text { Epigeic earthworm, } \\
\text { Perionyx excavatus } \\
\text { and an endogeic, } \\
\text { Glyphidrilus } \\
\text { spelaeotes }\end{array}$ & $\begin{array}{l}\text { Annelida-Clitellata- } \\
\text { Haplotaxida- } \\
\text { Megascolecidae: Perionyx } \\
\text { excavates, } \\
\text { Annelida-Clitellata- } \\
\text { Haplotaxida-Almidae: } \\
\text { Glyphidrilus spelaeotes }\end{array}$ & $\begin{array}{l}\text { Mycobacterium sp., } \\
\text { Stenotrophomonas sp., } \\
\text { Acinetobacter sp., } \\
\text { Alcaligenes sp., } \\
\text { Chryseobacterium sp., } \\
\text { Acinetobacter sp., } \\
\text { Pseudomonas sp., } \\
\text { Bacillus sp. and } \\
\text { Sphingomonas sp. }\end{array}$ & Filter paperase & {$[130]$} \\
\hline $\begin{array}{l}\text { Giant African land } \\
\text { snail Achatina fulica }\end{array}$ & $\begin{array}{l}\text { Mollusca- Gastropoda- } \\
\text { Stylommatophora- } \\
\text { Achatinidae }\end{array}$ & $\begin{array}{l}\text { Bacillus subtillis, } \\
\text { Achromobacter, sp., } \\
\text { Ochrobactrum sp.and } \\
\text { Klebsiella sp. }\end{array}$ & $\begin{array}{l}\text { endoglucanase, exoglucanase, } \\
\text { xylanase }\end{array}$ & [14] \\
\hline
\end{tabular}




\begin{tabular}{|c|c|c|c|c|}
\hline Species name & Systematic position & Bacterial strains identified & $\begin{array}{l}\text { Cellulolytic enzyme activity of } \\
\text { the culture Supernatant of the } \\
\text { isolated bacterial strains }\end{array}$ & Reference \\
\hline $\begin{array}{l}\text { Giant African land } \\
\text { snail Achatina fulica }\end{array}$ & $\begin{array}{l}\text { Mollusca- Gastropoda- } \\
\text { Stylommatophora- } \\
\text { Achatinidae }\end{array}$ & $\begin{array}{l}\text { Many genera had been isolated } \\
\text { which were belonged to three } \\
\text { phyla, namely Proteobacteria, } \\
\text { Actinoibacteria, and Firmicutes }\end{array}$ & \begin{tabular}{|l|} 
p-nitrophenyl-b-D- \\
cellobioside(pNPC), 4- \\
methylumbelliferyl- \\
b-D-cellobioside(MUC), 4- \\
methylumbelliferyl-b-D- \\
glucopyranoside(MUG), p- \\
nitrophenyl-b-D- \\
glucopyranoside(pNPG), 4- \\
methylumbelliferyl- \\
b-D-xylopyranoside(MUX), \\
powdered sugarcane bagasse and \\
CMC hydrolyting enzymes \\
(Enzyme activities were detected \\
by plate assay mehod)
\end{tabular} & [145] \\
\hline $\begin{array}{l}\text { Giant African land } \\
\text { snail Achatina fulica }\end{array}$ & $\begin{array}{l}\text { Mollusca- Gastropoda- } \\
\text { Stylommatophora- } \\
\text { Achatinidae } \\
\end{array}$ & Not identified & CMC-ase & [146] \\
\hline $\begin{array}{l}\text { Giant African land } \\
\text { snail Achatina fulica }\end{array}$ & $\begin{array}{l}\text { Mollusca- Gastropoda- } \\
\text { Stylommatophora- } \\
\text { Achatinidae }\end{array}$ & $\begin{array}{l}\text { Micrococcus sp., } \\
\text { Enterobacter sp. and } \\
\text { Yokenella sp. }\end{array}$ & $\begin{array}{l}\text { CMC-ase, filter paperase, } \\
\text { Xylanase }\end{array}$ & [147] \\
\hline $\begin{array}{l}\text { Giant African } \\
\text { snailArchachatina } \\
\text { marginata }\end{array}$ & $\begin{array}{l}\text { Mollusca- Gastropoda- } \\
\text { Stylommatophora- } \\
\text { Achatinidae }\end{array}$ & $\begin{array}{l}\text { Bacillus subtilis, } \\
\text { Streptococcus casseliflavus, } \\
\text { Streptococcus faecalis and } \\
\text { Staphylococcus aureus, }\end{array}$ & CMC-ase, protease & [148] \\
\hline $\begin{array}{l}\text { Giant African land } \\
\text { snail } \\
\text { Archachatina } \\
\text { marginata }\end{array}$ & $\begin{array}{l}\text { Mollusca- Gastropoda- } \\
\text { Stylommatophora- } \\
\text { Achatinidae }\end{array}$ & $\begin{array}{l}\text { Staphyloccus aureus, } \\
\text { Baccillus subtilis, } \\
\text { Streptobacillus sp., } \\
\text { Streptococcus aureus and } \\
\text { Escherichia coli, }\end{array}$ & $\begin{array}{l}\text { cellulase, } \alpha \text {-glucosidase, } \\
\text { amylase, proteinase, and lipase }\end{array}$ & [149] \\
\hline $\begin{array}{l}\text { Marine turban } \\
\text { shellBatillus cornutus }\end{array}$ & $\begin{array}{l}\text { Mollusca- Gastropoda- } \\
\text { Trochida-Turbinidae }\end{array}$ & $\begin{array}{l}\text { Bacillus sp. and } \\
\text { Staphylococcus sp. }\end{array}$ & $\begin{array}{l}\text { carboxymethyl cellulase, } \alpha- \\
\text { cellulase, laminarinase and kelp- } \\
\text { lyase }\end{array}$ & [153] \\
\hline
\end{tabular}

Table 2. Specific activity of several cellulolytic enzymes obtained from gut microbial flora of several lower invertebrate species.

\begin{tabular}{|c|c|c|c|}
\hline Invertebrate species & Gut microbial flora & $\begin{array}{l}\text { Specific activity of enzyme obtained from gut } \\
\text { microbial flora (maximum activities showed within } \\
\text { the incubation period of bacteria culture, are } \\
\text { mentioned here) }\end{array}$ & Reference \\
\hline \multirow{2}{*}{ Termite Cryptotermes brevis } & Bacillus sp. & $\begin{array}{l}\text { xylanase activity: } 0.21 \mathrm{U} / \mathrm{mL} \\
\text { CMCase activity: } 0.25 \mathrm{U} / \mathrm{mL}\end{array}$ & \multirow{2}{*}[83]{} \\
\hline & Ochrobactrum oryzae & $\begin{array}{l}\text { lignin peroxidase activity: } 14.6 \mathrm{IU} / \mathrm{mL} \\
\text { laccase activity: of } 8 \mathrm{IU} / \mathrm{mL}\end{array}$ & \\
\hline \multirow{5}{*}{$\begin{array}{l}\text { Termite Psammotermes } \\
\text { hypostoma }\end{array}$} & Paenibacillus lactis & endoglucanase activity: $1.47 \mathrm{U} / \mathrm{ml}$ & \multirow{5}{*}[84]{} \\
\hline & Lysinibacillus fusiformis & endoglucanase activity: $0.22 \mathrm{U} / \mathrm{ml}$ & \\
\hline & $\begin{array}{l}\text { Stenotrophomonas } \\
\text { maltophilia }\end{array}$ & endoglucanase activity: $2.28 \mathrm{U} / \mathrm{ml}$ & \\
\hline & Lysinibacillus macrolides & endoglucanase activity: $1.93 \mathrm{U} / \mathrm{ml}$ & \\
\hline & Bacillus cereus & endoglucanase activity: $0.23 \mathrm{U} / \mathrm{ml}$ & \\
\hline \multirow{3}{*}{ Termite Amitermes evuncifer } & Bacillus cereus & $\begin{array}{l}\text { endoglucanase activity: } 6.38 \mu \mathrm{mol} \mathrm{min}-1 \mathrm{mg}-1 \\
\text { exoglucanase activity: } 1.14 \mu \mathrm{mol} \mathrm{min}-1 \mathrm{mg}-1\end{array}$ & \multirow{3}{*}[85]{} \\
\hline & Bacillus mycoides & $\begin{array}{l}\text { endoglucanase activity: } 5.96 \mu \mathrm{mol} \mathrm{min}-1 \mathrm{mg}-1 \\
\text { exoglucanase activity: } 1.08 \mu \mathrm{mol} \mathrm{min}-1 \mathrm{mg}-1\end{array}$ & \\
\hline & Pseudomonas aeruginosa & $\begin{array}{l}\text { endoglucanase activity: } 4.89 \mu \mathrm{mol} \mathrm{min}-1 \mathrm{mg}-1 \\
\text { exoglucanase activity: } 1.47 \mu \mathrm{mol} \mathrm{min}-1 \mathrm{mg}-1\end{array}$ & \\
\hline \multirow{2}{*}{ Termite Macrotermes gilvus } & Provedenciasp. & cellulase activity: $15.7 \mathrm{mU} / \mathrm{mL}$ & \multirow{2}{*}{$-[86]$} \\
\hline & Bacillus sp. & cellulase activity: $2.33 \mathrm{mU} / \mathrm{mL}$ & \\
\hline $\begin{array}{l}\text { Termite Nasutitermes } \\
\text { takasagoensis }\end{array}$ & Not identified & $\begin{array}{l}\text { endoglucanase (CMCase) activity: } 2.40 \text { units } / \mathrm{mg} \\
\beta \text {-glucosidase (cellobiase) activity: } 0.36 \text { units/ mg } \\
\text { (one unit is the amount of enzyme that produce } 1 \mu \mathrm{mol} \\
\text { glucose or glucose equivalent/min) }\end{array}$ & ]$^{[116]}$ \\
\hline $\begin{array}{l}\text { Termite, catterpiller and book } \\
\text { worm }\end{array}$ & Not identified & $\begin{array}{l}\text { endoglucanase activity: } 0.400 \mathrm{IU} / \mathrm{mL} \text { extract } \\
\text { filter papersae activity: } 0.194 \mathrm{IU} / \mathrm{mL} \text { extract }\end{array}$ & {$[160]$} \\
\hline Termite & Not identified & $\begin{array}{l}\text { CMC-ase activity: } 0.0155 \mathrm{IU} / \mathrm{ml} \\
\text { filter paperase activity: } 0.004 \mathrm{IU} / \mathrm{ml}\end{array}$ & {$[163]$} \\
\hline Holotrichia parallela larvae & Pseudomonas sp. & endoglucanase activity: $0.825 \mathrm{U} / \mathrm{mL}$ & {$[90]$} \\
\hline \multicolumn{3}{|c|}{ https://biointerfaceresearch.com/ } & 13625 \\
\hline
\end{tabular}




\begin{tabular}{|c|c|c|c|}
\hline $\begin{array}{l}\text { Beetle Osphranteria } \\
\text { coerulescenslarvae }\end{array}$ & Bacillus sp. & CMC-ase activity: $4.99 \mathrm{U} / \mathrm{mL}$ & {$[98]$} \\
\hline \multirow{2}{*}{$\begin{array}{l}\text { Moth Diatraea saccharalis } \\
\text { larvae }\end{array}$} & Bacillus pumilus & $\begin{array}{l}\text { CMC-ase activity: } 0.32 \mathrm{U} / \mathrm{mL} \\
\text { enzyme activity on sugarcane biomass: } 0.23 \mathrm{U} / \mathrm{mL}\end{array}$ & \multirow{2}{*}[100]{} \\
\hline & Klebsiella oxytoca & $\begin{array}{l}\text { CMC-ase activity: } 0.22 \mathrm{U} / \mathrm{mL} \\
\text { enzyme activity on sugarcane biomass: } 0.13 \mathrm{U} / \mathrm{mL}\end{array}$ & \\
\hline \multirow{3}{*}{$\begin{array}{l}\text { Moth Diatraea } \\
\text { saccharalislarvae }\end{array}$} & Klebsiella pneumoniae & cellulase activity of protein extract:30.13 U/mg & \multirow{3}{*}[101]{} \\
\hline & Klebsiella sp. & cellulase activity of protein extract: $19.97 \mathrm{U} / \mathrm{mg}$ & \\
\hline & Bacillus sp. & cellulase activity of protein extract:5.53 U/mg & \\
\hline Sikworm Bombyx morilarvae & Bacillus aryabhattai & $\begin{array}{l}\text { cellulase activity: } 0.4 \mathrm{U} / \mathrm{mL} \\
\text { (values is approximated from the graphical } \\
\text { representation) }\end{array}$ & $1[103]$ \\
\hline $\begin{array}{l}\text { Mole crickets Gryllotalpa } \\
\text { africana }\end{array}$ & Acinetobacter junii & CMCase activity: $0.35 \mathrm{U} / \mathrm{ml}$ & [106] \\
\hline Rice weevil Sitophilus oryzae & Bacillus subtilis & cellulase (endoglucanase activity $132.069 \pm 0.993 \mathrm{U} / \mathrm{mL}$ & {$[107]$} \\
\hline Earthworm Eudrilus eugeniae & Bacillus pumilus & cellulase (endoglucanase) activity: $0.1271 \mathrm{IU} / \mathrm{mL}$ & [124] \\
\hline Earthworm Eisenia foetida & Lysinibacillus sphaericus & $\begin{array}{l}\text { cellulase activity } 1.92 \mathrm{FPU} / \mathrm{mL} \\
\text { (cellulase activity was expressed here in terms of Filter } \\
\text { Paper Units (FPU) }\end{array}$ & {$[128]$} \\
\hline Earthworm Eisenia fetida & Not identified & $\begin{array}{l}\text { CMC-ase activity: } 26.041 \mathrm{IU} / \mathrm{mL} \text { and } 47.80 \mathrm{IU} / \mathrm{mL} \\
\text { produced by two different culture }\end{array}$ & {$[129]$} \\
\hline $\begin{array}{l}\text { Epigeic earthworm, Perionyx } \\
\text { excavatus and an endogeic, } \\
\text { Glyphidrilus spelaeotes }\end{array}$ & $\begin{array}{l}\text { Mycobacterium sp. } \\
\text { Stenotrophomonas sp. } \\
\text { Acinetobacter sp. } \\
\text { Alcaligenes sp. } \\
\text { Chryseobacterium sp. } \\
\text { Acinetobacter sp. } \\
\text { Pseudomonas sp. } \\
\text { Bacillus sp. } \\
\text { Sphingomonas sp. }\end{array}$ & $\begin{array}{l}\text { The highest cellulase (filter paperase) activity of these } \\
\text { carbohydrate degrading bacteria was ranged from } 0.42 \text { to } \\
0.59 \mu \mathrm{M} \text { glucose } \mathrm{ml}^{-1} \mathrm{~min}^{-1} \\
\text { (The cellulase enzyme activity was determined here as } \\
\text { glucose equivalent) }\end{array}$ & {$[130]$} \\
\hline \multirow{7}{*}{ Achatina fulica } & Bacillus subtilis & $\begin{array}{l}\text { endoglucnase activity: } \\
\text { 230.86 IU/mL gut extract for CMC substrate }\end{array}$ & {$[14]$} \\
\hline & Ochrobactrum sp. & $\begin{array}{l}\text { endoglucanase activity } \\
502.75 \mathrm{IU} / \mathrm{mL} \text { gut extract for grass straw as substrate } \\
347.65 \mathrm{IU} / \mathrm{mL} \text { gut extract for wheat husk as a substrate } \\
112.68 \mathrm{IU} / \mathrm{mL} \text { gut extract for filter paper as a substrate }\end{array}$ & \\
\hline & Bacillus subtilis & $\begin{array}{l}\text { exoglucanase activity: } \\
3777.61 \mathrm{IU} / \mathrm{mL} \text { extract for filter paper as a substrate }\end{array}$ & \\
\hline & Ochrobactrum sp. & $\begin{array}{l}\text { exoglucanase activity: } \\
2406.31 \mathrm{IU} / \mathrm{mL} \text { extract for wheat husk as a substrate }\end{array}$ & \\
\hline & Bacillus subtilis & $\begin{array}{l}\text { xylanase activity: } \\
60.22 \mathrm{IU} / \mathrm{mL} \text { extract) on wheat husk as a substrate }\end{array}$ & \\
\hline & Ochrobactrum sp. & $\begin{array}{l}\text { xylanase activity: } \\
\text { 82.03 IU/mL extract for grass straw as substrate } \\
24.23 \mathrm{IU} / \mathrm{mL} \text { extract for filter paper as a substrate }\end{array}$ & \\
\hline & Aspergillus niger & $\begin{array}{l}\text { cellulase (CMCase) activity from fungal isolates } 14.46 \\
\mathrm{mg} / \mathrm{ml} \mathrm{sec}^{-4}\end{array}$ & \\
\hline Achatina fulica & Not identified & CMCase activity: $0.4539 \mathrm{U} / \mathrm{mL}$ & {$[146]$} \\
\hline \multirow{2}{*}{ Achatina fulica } & Enterobacter sp. & $\begin{array}{l}\text { filter paperase activity: } 5 \mathrm{U} / \mathrm{ml} \\
\text { CMC-ase activity: } 2.5 \mathrm{U} / \mathrm{ml} \\
\text { xylanase activity: } 0.6 \mathrm{U} / \mathrm{ml} \\
\text { (values are approximated from the graphical } \\
\text { representation) }\end{array}$ & {$[147]$} \\
\hline & Yokenella sp. & $\begin{array}{l}\text { filter paperase activity: } 3 \mathrm{U} / \mathrm{ml} \\
\text { CMC-ase activity: } 4 \mathrm{U} / \mathrm{ml} \\
\text { xylanase activity: } 0.7 \mathrm{U} / \mathrm{ml} \\
\text { (values are approximated from the graphical } \\
\text { representation) }\end{array}$ & \\
\hline \multirow{4}{*}{ Archachatina marginata } & Bacillus subtilis & cellulase (CMCase) activity: $2.2 \mathrm{mg} / \mathrm{mL} \mathrm{sec}^{-4}$ & [148] \\
\hline & Streptococcus casseliflavus & cellulase (CMCase) activity: $1.7 \mathrm{mg} / \mathrm{mL} \mathrm{sec}^{-4}$ & \\
\hline & Streptococcus faecalis & cellulase (CMCase) activity: $1.4 \mathrm{mg} / \mathrm{mL} \mathrm{sec}^{-4}$ & \\
\hline & Staphylococcus aureus & cellulase (CMCase) activity: $0.2 \mathrm{mg} / \mathrm{mL} \mathrm{sec}^{-4}$ & \\
\hline Achatina marginata & $\begin{array}{l}\text { Staphyloccus aureus, } \\
\text { Baccillus subtilis, } \\
\text { Streptobacillus sp., } \\
\text { Streptococcus aureus, } \\
\text { Escherichia coli }\end{array}$ & $\begin{array}{l}\text { amylase activity: } 18.40 \mathrm{mg} / \mathrm{g} \\
\text { lipase activity: } 15.80 \mathrm{mg} / \mathrm{g} \\
\text { cellulase activity: } 13.20 \mathrm{mg} / \mathrm{g} \\
\text { proteinase activity: } 13 \mathrm{mg} / \mathrm{g} \\
\alpha \text {-glucosidase activity: } 8.30 \mathrm{mg} / \mathrm{g}\end{array}$ & [149] \\
\hline
\end{tabular}




\begin{tabular}{|c|c|c|c|}
\hline & & $\begin{array}{l}\text { (enzyme activity was assessed from the gut homogenate, } \\
\text { maximum enzyme activity of adult snails are mentioned } \\
\text { here) }\end{array}$ & \\
\hline Sea snail Batillus cornutus & Bacillus sp. & $\begin{array}{l}\text { CM-cellulase activity: } 22.76 \mathrm{U} / \mathrm{mg} \text { protein } \\
\alpha \text {-cellulase activity: } 27.10 \mathrm{U} / \mathrm{mg} \text { protein } \\
\text { laminarinase activity: } 66.59 \mathrm{U} / \mathrm{mg} \text { protein } \\
\text { kelp-lyase activity: } 64.36 \mathrm{U} / \mathrm{mg} \text { protein }\end{array}$ & [153] \\
\hline
\end{tabular}

To obtain efficient hydrolytic potential, cellulase enzymes should possess some desired attributes, including high specific activity, high catalytic activity against crystalline cellulose, high thermostability, resistance to end-product inhibition, and stability against shear force [164]. Various genetic tools are being used for microbial strain improvement to achieve these attributes and enhance enzyme production. Several industrially used fungal strains such as $A$. niger, T. reesei, Saccharomyces cerevisae, Pichia pastoris, and bacterial strains like Escherichia coli, Bacillus subtilis [164] have subjected to genetic engineering for the production of a recombinant enzyme with high potential for industrial application. Homologous and heterologous expression techniques have been adopted in the recent era to overexpress microbial cellulase and other hydrolytic enzymes [164]. Owing to the genetic engineering of the cellulolytic microbial strain, cellulose-degrading enzymes' efficient production has enhanced its biotechnological potential in various industrial fields. A brief account of the application of cellulase and allied enzymes have been discussed here.

\subsection{Food processing industry.}

The application of enzymes in the extraction of fruit juices and pulps mitigates the problem of low yield, stability, and clarity of product, which are the main difficulties faced by the food industries in the early 1930s. Later on, progressive research on enzyme technology leads to the production of cellulase, hemicellulase, and pectinase from the food-grade microorganisms A. niger and T. reesei. A combination of these enzymes (pectinase, cellulase, hemicellulase), also called macerating enzymes, plays an important role in the extraction and clarification of vegetable and fruit juices [1] also improves the stability and textures of the purees and pulp. A mixture of pectinase and a low level of hemicellulase and cellulase, commercially know as Olivex is used to extract olive oil from olive seeds. The use of Olivex improves the quality of olive oil extract by enriching extra virgin olive oil with vitamin $\mathrm{E}$ and antioxidants, reducing the induction of rancidity and lowering oil content in the wastewater [165]. Infusion of pectinase enzyme helps in peeling of citrus food by reducing its bitterness. Application of $\beta$-glucosidase and pectinase ameliorate the texture, aroma, flavor, and volatiles compounds of specific fruits and vegetables [166]. Microbial enzymes are long being used in the quality improvement of bakery products also. Amylases and proteases are mainly used in the bakery industry [167], but recently the use of hemicellulase and endo-xylanase helps in equal distribution of water in dough and bread by hydrolyzing arabinoxylan present in dough [168]. This redistribution of water facilitates the enhancement of flavor, volume, softness, texture, and bakery products' stability.

\subsection{Brewery and winery industry.}

The application of exogenous enzymes in wine and beer biotechnology playsa key role in quality control and production rate. $\alpha$ and $\beta$-amylase, carboxypeptidase, and $\beta$-glucanase are endogenously synthesized during the germination of barley before malting and synergistically act hydrolyze seed reserves during the malting process. But their improper activities often result in un-malted and poor quality barley. Application of microbial $\beta$-glucanase facilitates 
hydrolysis of $\beta$-glucan and reduces the wort viscosity during the maceration and fermentation process of barley. In the winery, exogenous enzymes hemicellulase, pectinase, $\beta$-glucanase are used for better maceration, improved color extraction, filtration and clarification, and wine stability and quality [165]. Furthermore, the $\beta$-glucosidase enzyme application modifies glycosylated precursors that enhance the aroma of wine [169].

\subsection{Paper and pulp industry.}

Application of biomechanical pulping process using enzymes instead of the only mechanical process reduces the energy expenditure during grinding and refining of the woody material in pulps. Mixtures of endoglucanase I and II and hemicellulase have been used to better drainage and beat ability in the paper mills before or after beating pulp, which in turn increases the overall production rate [1]. Cellulase and xylanase enhance the bleaching and deinking of several types of paper wastes [170]. Overall addition of several hydrolytic enzymes ameliorates fiber brightness, strength properties, pulp freeness, and cleanliness.

\subsection{Textile and laundry industry.}

The application of cellulase in the bio-stoning process of denim and jeans products has achieved great success. Usage of cellulase in bio polishing of cotton fabric also has an advantage as an enzyme can readily remove surface fibers and fuzz, resulting in the glossy, smooth, and brighter appearance of cotton garments [1,165]. Cotton garments usually become fluffy and dull after repeated wash. The addition of cellulase enzyme in household detergents helps remove fluffy fibrils from cotton, boosting the appearance and brightness of the garments [1].

\subsection{Animal feed.}

In the animal feed industry, cellulase plays a key role in removing Anti-nutritional Factors (ANF) from the cereals, grains, and vegetables used for animal feed in poultry, cattle, and fish farming. Pretreatment with cellulase and hemicellulase induces partial digestion of lignocellulosic materials and $\beta$-glucans, dehulling cereal grains, which improves the cereal quality and ensures a high yield of milk and meat production [165].

\subsection{Research development and agriculture.}

A combination of hydrolytic enzymes, including cellulase, hemicellulase, ligninase, have an immense effect on plant growth and plant disease control [1]. Cellulases and $\beta$ glucanases can degrade the cell wall and inhibit the germination of spores of some phytopathogens. Mixtures of different hydrolytic enzymes facilitate the digestion of desired plant or fungal cell walls to produce protoplast, which can be used to make hybrid strains of desired properties for research purposes [23].

\subsection{Waste management.}

As cellulose is the most abundant biomolecules in the plant, a large number of wastes of leaf litter and other lignocellulosic materials are generated from forests, agricultural fields, and agro-industries. These wastes containing a large amount of raw cellulose may cause environmental pollution. But nowadays, with the help of enzyme technology, these unutilized 
or underutilized cellulosic sources are being converted to produce several biofuels and bio commodities, sugars, and alcohol [1,171,172]. Application of garden snail (Cornu aspersum) cellulase in paper waste saccharification is empirical evidence of cellulase activity in waste management [173].

\section{Conclusion and Future Prospect}

Cellulase and allied enzymes are getting attraction worldwide due to their wide range of applications in vast areas of industries. Although in the past, fungal-based enzymatic systems have been used for cellulolytic enzyme production, later many research works have been carried out in search of more efficient microbial enzymatic systems as a source of cellulolytic enzymes. Bacterial enzymatic systems are more promising due to enzyme complexity, extreme habitat variability, and low production cost. Researchers are focusing on bacterial strain improvement to obtain tailor-made cellulolytic enzymes with high specific activity and catalytic efficiency with the aid of biotechnology and enzymology. Moreover, identifying newer sources of cellulose-degrading microorganisms is essential for the isolation of novel cellulolytic genes. Previous studies assert that the gut of phytophagous and herbivorous invertebrates is the host of the cellulolytic bacterial niche. In the future, further exploration of such invertebrates is necessary for the isolation of novel bacteria, which will bring great prospects in the industrial application of cellulolytic enzymes.

\section{Funding}

This research received no external funding.

\section{Acknowledgments}

The authors are grateful to the respective heads of the Department of Zoology and Department of Botany, the University of Calcutta, for providing facilities to carry out the work.

\section{Conflicts of Interest}

The authors declare no conflict of interest.

\section{References}

1. Bhat, M.K. Cellulases and related enzymes in biotechnology. Biotechnol. Adv. 2000, 18, 355-383, https://doi.org/10.1016/S0734-9750(00)00041-0.

2. $\quad$ Bashir, Z.; Kondapalli, V.K.; Adlakha, N.; Sharma, A.; Bhatnagar, R.K.; Chandel, G.; Yazdani, S.S. Diversity and functional significance of cellulolytic microbes living in termite, pill-bug and stem-borer guts. Sci. Rep.2013, 2558, https://doi.org/10.1038/srep02558.

3. Snáchez, O.J.; Cardona, C.A.Trends in biotechnological production of fuel ethanol from different feedstocks. Bioresour. Technol. 2008, 99, 5270-5295, https://doi.org/10.1016/j.biortech.2007.11.013.

4. Himmel, M.E.; Bayer, E.A.Lignocellulose conversion to biofuels: current challenges, global perspectives. Curr. Opin. Biotechnol. 2009, 20, 316-317, https://doi.org/10.1016/j.copbio.2009.05.005.

5. Jäger, G.; Büchs, J.Biocatalytic conversion of lignocellulose to platform chemicals. Biotechnol. J. 2012, 7, 1122-1136, https://doi.org/10.1002/biot.201200033.

6. Anu; Kumar, A.; Rapoport, A.; Kunze, G.; Kumar, S.; Singh, D.; Singh, B. Multifarious pretreatment strategies for the lignocellulosic substrates for the generation of renewable and sustainable biofuels: a review. Renew. Energy 2020, 160, 1228-1252, https://doi.org/10.1016/j.renene.2020.07.031.

7. Chakraborti, M.; Acharya, K. Agrowaste to ethanol: orchestrated by enzymes from microbes. In:Microbial Fermentation and Enzyme Technology. CRC Press, 2020. 
8. Kaur, P.; Taggar, M.S.; Kaur, J. Cellulolytic microorganisms: diversity and role in conversion of rice straw to bioethanol. Cell. Chem.Technol. https://doi.org/10.35812/CelluloseChemTechnol.2020.54.61.

9. Khandaker, M.M.; Abdullahi, U.A.; Abdulrahman, M.D.; Badaluddin, N.A.; Mohd, K.S. Bio-ethanol production from fruit and vegetable waste by using Saccharomyces cerevisiae. In: Bioethanol. IntechOpen, 2020, https://doi.org/10.5772/intechopen.94358.

10. Rajeswari, K.; Rekha, B.; Saravanathamizhan, R. Promotion of enzymatic hydrolysis of lignocellulosic biomass using natural additives for bioethanol production. Environ. Qual. Manage. 2020, 1-7, https://doi.org/10.1002/tqem.21705.

11. Singh, V.P.; Sharma, D.; Prajapati, S.; Bamal, A.; Tyagi, S. A comparative study of cellulase production: minireview. J. Sci. Innov. Res.2020, 9, 69-73.

12. Tsegaye, B.; Balomajumder, C.; Roy, P. Organosolv pretreatments of rice straw followed by microbial hydrolysis for efficient biofuel production. Renew. Energy 2020, 148,923-934, https://doi.org/10.1016/j.renene.2019.10.176.

13. Cardoso, A.M.; Cavalcante, J.J.; Cantão, M.E.; Thompson, C.E.; Flatschart, R.B.; Glogauer, A.; Scapin, S.M.; Sade, Y.B.; Beltrão, P.J.; Gerber, A.L.; Martins, O.B. Metagenomic analysis of the microbiota from the crop of an invasive snail reveals a rich reservoir of novel genes. PLoS One 2012, 7,https://doi.org/10.1371/journal.pone.0048505.

14. Dar, M.A.; Pawar, K.D.; Jadhav, J.P.; Pandit, R.S. Isolation of cellulolytic bacteria from the gastro-intestinal tract of Achatina fulica (Gastropoda: Pulmonata) and their evaluation for cellulose biodegradation. Int. Biodeterior. Biodegrad. 2015, 98, 73-80, https://doi.org/10.1016/j.ibiod.2014.11.016.

15. Badger, P.C. Ethanol from cellulose: a general review. Trends in New Crops and New Uses 2002, 1, 17-21.

16. Liu, L.; Jiao, J.Y.; Fang, B.Z.; Lv, A.P.; Ming, Y.Z.; Li, M.M.; Salam, N.; Li, W.J. Isolation of Clostridium from Yunnan-Tibet hot springs and description of Clostridium thermarum sp. nov. with lignocellulosic ethanol production. Syst. Appl. Microbiol.2020, 43, https://doi.org/10.1016/j.syapm.2020.126104.

17. Goldemberg, J.The Brazilian biofuels industry. Biotechnol. Biofuels. 2008, 1, 6-13, https://doi.org/10.1186/1754-6834-1-6.

18. Somerville, C.; Youngs, H.; Taylor, C.; Davis, S.C.; Long, S.P. Feedstocks for lignocellulosic biofuels. Science 2010, 329, 790-792, https://doi.org/10.1126/science.1189268.

19. Vandenbossche, V.; Brault, J.; Vilarem, G.; Hernández-Meléndez, O.; Vivaldo-Lima, E.; Hernández-Luna, M.; Barzana, E.; Duque, A.; Manzanares, P.; Ballesteros, M.; Mata, J. A new lignocellulosic biomass deconstruction process combining thermo-mechano chemical action and bio-catalytic enzymatic hydrolysis in a twin-screw extruder. Ind. Crops. Prod. 2014, 55, 258-266, https://doi.org/10.1016/j.indcrop.2014.02.022.

20. Prasad, R.K.; Chatterjee, S.; Sharma, S.; Mazumder, P.B.; Vairale, M.G.; Raju, P.S. Insect gut bacteria and their potential application in degradation of lignocellulosic biomass: a review. In: Bioremediation: applications for environmental protection and management. Varjani, S.J.; Agarwal, A.K.; Gnansounou, E.; Gurunathan, B. (eds.).Springer, Singapore, 2018; pp. 277-299, https://doi.org/10.1007/978-981-10-7485$1 \_14$.

21. Houfani, A.A.; Anders, N.; Spiess, A.C.; Baldrian, P.; Benallaoua, S. Insights from enzymatic degradation of cellulose and hemicellulose to fermentable sugars-a review. Biomass Bioenergy 2020, 134, https://doi.org/10.1016/j.biombioe.2020.105481.

22. Phan, P.T.; Nguyen, B.S.; Nguyen, T.A.; Kumar, A.; Nguyen, V.H. Lignocellulose-derived monosugars: a review of biomass pre-treating techniques and post-methods to produce sustainable biohydrogen. Biomass. Convers. Biorefin. 2020, 1-15, https://doi.org/10.1007/s13399-020-01161-7.

23. Béguin, P.; Aubert, J.P. The biological degradation of cellulose. FEMS Microbiol. Rev. 1994, 13, 25-58, https://doi.org/10.1111/j.1574-6976.1994.tb00033.x.

24. Kuhad, R.C.; Gupta, R.; Singh, A. Microbial cellulases and their industrial applications. Enzyme Res. 2011, 2011, 1-10, http://dx.doi.org/10.4061/2011/280696.

25. Karmakar, M.; Ray, R.R. Current trends in research and application of microbial cellulases. Res. J. Microbiol. 2011, 6, 41-53, https://dx.doi.org/10.3923/jm.2011.41.53.

26. Menéndez, E.; Ramírez-Bahena, M.H.; Fabryová, A.; Igual, J.M.; Benada, O.; Mateos, P.F.; Peix, A.; Kolařík, M.; García-Fraile, P.Pseudomonas coleopterorumsp. nov., a cellulase-producing bacterium isolated from the bark beetle Hylesinus fraxini. Int. J. Syst. Evol. Microbiol. 2015, 65, 2852-2858, https://doi.org/10.1099/ijs.0.000344.

27. Bajaj, P.; Mahajan, R. Cellulase and xylanase synergism in industrial biotechnology. Appl. Microbiol. Biotechnol. 2019, 103, 8711-8724, https://doi.org/10.1007/s00253-019-10146-0.

28. Chakraborty, D.; Sarkar, N.; Biswas, I.; Jacob, S. Molecular aspects of prokaryotic and eukaryotic cellulases and their modulation for potential application in biofuel production. In:Genetic and Metabolic Engineering for Improved Biofuel Production from Lignocellulosic Biomass. Elsevier, 2020; pp. 81-95, https://doi.org/10.1016/B978-0-12-817953-6.00006-3.

29. Piskur, J.; Rozpedowska, E.; Polakova, S.; Merico, A.; Compagno, C. How did Saccharomyces evolve to become a good brewer? TrendsGenet. 2006, 22, 183-186, https://doi.org/10.1016/j.tig.2006.02.002. 
30. Huang, S.; Sheng, P.; Zhang, H. Isolation and identification of cellulolytic bacteria from the gut of Holotrichia parallela larvae (Coleoptera: Scarabaeidae). Int. J. Mol. Sci. 2012, 13, 2563-2577, https://doi.org/10.3390/ijms13032563.

31. Oh, E.J.; Jin, Y.S. Engineering of Saccharomyces cerevisiae for efficient fermentation of cellulose. FEMS Yeast Res. 2020, 20,https://doi.org/10.1093/femsyr/foz089.

32. Walker, G.M.; Basso, T.O. Mitigating stress in industrial yeasts. Fungal Biol. 2020, 124, 387-97, https://doi.org/10.1016/j.funbio.2019.10.010.

33. Claes, A.; Deparis, Q.; Foulquié-Moreno, M.R.; Thevelein, J.M. Simultaneous secretion of seven lignocellulolytic enzymes by an industrial second-generation yeast strain enables efficient ethanol production from multiple polymeric substrates. Metab. Eng. 2020, 59, 131-141, https://doi.org/10.1016/j.ymben.2020.02.004.

34. Eardley, J.; Timson, D.J. Yeast cellular stress: impacts on bioethanol production. Ferment. 2020, 6, https://doi.org/10.3390/fermentation6040109.

35. Mihajlovski, K.; Buntić, A.; Milić, M.; Rajilić-Stojanović, M.; Dimitrijević-Branković, S. From agricultural waste to biofuel: enzymatic potential of a bacterial isolate Streptomyces fulvissimus CKS7 for bioethanol production. Waste Biomass Valorization 2020,12, 165-174, https://doi.org/10.1007/s12649-020-00960-3.

36. Thapa, S.; Mishra, J.; Arora, N.; Mishra, P.; Li, H.; O'Hair, J.; Bhatti, S.; Zhou, S. Microbial cellulolytic enzymes: diversity and biotechnology with reference to lignocellulosic biomass degradation. Rev. Environ. Sci. Biotechnol. 2020, 19, 621-648, https://doi.org/10.1007/s11157-020-09536-y.

37. Amore, A.; Pepe, O.; Ventorino, V.; Aliberti, A.; Faraco, V. Cellulolytic Bacillus strains from natural habitats -a review. Chimica Oggi/ Chemistry Today 2013, 31, 49-52.

38. Amore, A.; Pepe, O.; Ventorino, V.; Birolo, L.; Giangrande, C.; Faraco, V. Industrial waste based compost as a source of novel cellulolytic strains and enzymes. FEMS. Microbiol. Lett. 2013, 339, 93-101, https://doi.org/10.1111/1574-6968.12057.

39. Saffari, H.; Pourbabaee, A.A.; Asgharzadeh, A.; Besharati, H. Isolation and identification of effective cellulolytic bacteria in composting process from different sources. Arch. Agron. Soil. Sci. 2017, 63, 297307, https://doi.org/10.1080/03650340.2016.1198006.

40. Harindintwali, J.D.; Zhou, J.; Yu, X. Lignocellulosic crop residue composting by cellulolytic nitrogen-fixing bacteria: a novel tool for environmental sustainability. Sci. Total Environ. 2020, 715,https://doi.org/10.1016/j.scitotenv.2020.136912.

41. Mahmood, R.; Afrin, N.; Jolly, S.N.; Shilpi, R.Y. Isolation and identification of cellulose-degrading bacteria from different types of samples. World J. Environ. Biosci.2020, 9, 8-13.

42. Watanabe, H.; Tokuda, G. Cellulolytic systems in insects. Annu. Rev. Entomol. 2010, 55, 609-632, https://doi.org/10.1146/annurev-ento-112408-085319.

43. Zhang, X.Z.; Zhang, Y.H.P.Cellulases: characteristics, sources, production, and applications. Bioprocessing Technologies in Biorefinery for Sustainable Production of Fuels, Chemicals, and Polymers 2013, 1, 131146, https://doi.org/10.1002/9781118642047.ch8.

44. Douglas, A.E. The microbial dimension in insect nutritional ecology. Funct. Ecol. 2009, 23, 38-47, https://doi.org/10.1111/j.1365-2435.2008.01442.x.

45. Jing, T.Z.; Qi, F.H.; Wang, Z.Y. Most dominant roles of insect gut bacteria: digestion, detoxification, or essential nutrient provision?Microbiome 2020, 8, 1-20, https://doi.org/10.1186/s40168-020-00823-y.

46. Bayer, E.A.; Belaich, J.P.; Shoham, Y.; Lamed, R. The cellulosomes: multienzyme machines for degradation of plant cell wall polysaccharides. Annu. Rev. Microbiol. 2004, 58, 521-554, https://doi.org/10.1146/annurev.micro.57.030502.091022.

47. Jayasekara, S.; Ratnayake, R. Microbial cellulases: an overview and applications. In:Cellulose. Intechopen, 2019; pp. 1-21, https://doi.org/10.5772/intechopen.84531.

48. Leo, V.V.; Ramesh, N.; Singh, B.P. Microorganisms as an efficient tool for cellulase production: availability, diversity, and efficiency. In:New and Future Developments in Microbial Biotechnology and Bioengineering. Elsevier, 2019; pp. 45-61, https://doi.org/10.1016/B978-0-444-64223-3.00004-7.

49. Nitisinprasert, S.; Temmes, A. The characteristics of a new non-spore-forming cellulolytic mesophilic anaerobe strain CM126 isolated from municipal sewage sludge. J. Appl. Bacteriol. 1991, 71, 154-161, https://doi.org/10.1111/j.1365-2672.1991.tb02972.x.

50. Ram, L.; Kaur, K.; Sharme, S. Screening, isolation and characterization of cellulase producing microorganisms from soil. Int. J. Pharm. Sci. Invent. 2014, 3, 12-18.

51. Magotra, S.; Magotra, M. S. Isolation of cellulose degrading bacteria from soil sample. PalArch's Journal of Archaeology of Egypt/Egyptology 2020, 17, 6099-6110.

52. Maravi, P.; Kumar, A. Isolation, screening and identification of cellulolytic bacteria from soil. Biotechnol.J. Int. 2020, 24, 1-8, https://doi.org/10.9734/BJI/2020/v24i130092.

53. Alavijeh, R.S.; Karimi, K.; van den Berg, C. An integrated and optimized process for cleaner production of ethanol and biodiesel from corn stover by Mucor indicus. J. Clean. Prod. 2019, 249,https://doi.org/10.1016/j.jclepro.2019.119321.

54. Coniglio, R.O.; Díaz, G.V.; Fonseca, M.I.; Castrillo, M.L.; Piccinni, F.E.; Villalba, L.L.; Campos, E.; Zapata, P.D. Enzymatic hydrolysis of barley straw for biofuel industry using a novel strain of Trametes villosa from 


Paranaense $\quad$ rainforest. $\quad$ Prep. $\quad$ Biochem. $\quad$ Biotech.
https://doi.org/10.1080/10826068.2020.1734941.

55. Ma, L.; Lu, Y.; Yan, H.; Wang, X.; Yi, Y.; Shan, Y.; Liu, B.; Zhou, Y.; Lü, X. Screening of cellulolytic bacteria from rotten wood of Qinling (China) for biomass degradation and cloning of cellulases from Bacillusmethylotrophicus. BMC Biotechnol. 2020, 20, 1-13, https://doi.org/10.1186/s12896-019-0593-8.

56. Naresh, S.; Kunasundari, B.; Gunny, A.A.N.; Teoh, Y.P.; Shuit, S.H.; Ng, Q. H.; Hoo, P.Y. Isolation and partial characterisation of thermophilic cellulolytic bacteria from north Malaysian tropical mangrove soil. Trop. Life Sci. Research 2019, 30, 123-147, https://doi.org/10.21315/tlsr2019.30.1.8.

57. Biswas, S.; Al Saber, M.; Tripty, I.A.; Karim, M.A.; Islam, M.A.; Hasan, M.S.; Alam, A.R.U.; Jahid, M.I.K.; Hasan, M.N. Molecular characterization of cellulolytic (endo-and exoglucanase) bacteria from the largest mangrove forest (Sundarbans), Bangladesh. Ann. Microbiol. 2020, 70, 1-11, https://doi.org/10.1186/s13213020-01606-4.

58. Chantarasiri, A. Diversity of cellulolytic bacteria isolated from a freshwater wetland reserve in Thailand and their cellulolytic activity. Appl. Ecol. Environ. Res. 2020, 18, 5965-5983, http://dx.doi.org/10.15666/aeer/1804_59655983.

59. Zhang, H.; Li, Q.; Zhao, Y.; Zhang, M.; Xu, D.; Wu, Z.; Zhou, Q. Endoglucanase activity of cellulolytic bacteria from lake sediments and its application in hydrophyte degradation. FEMS Microbiol. Lett. 2020, 367, https://doi.org/10.1093/femsle/fnaa200.

60. Hajiabadi, S.; Mashreghi, M.; Bahrami, A.R.; Ghazvini, K.; Matin, M.M. Isolation and molecular identification of cellulolytic bacteria from Dig Rostam hot spring and study of their cellulase activity. Biocell 2020, 44, 63-71, https://doi.org/10.32604/biocell.2020.08171.

61. Barzkar, N.; Sohail, M. An overview on marine cellulolytic enzymes and their potential applications. Appl. Microbiol. Biotechnol. 2020, 104, 6873-6892, https://doi.org/10.1007/s00253-020-10692-y.

62. Ren, W.; Xu, X.; Long, H.; Cai, X.; Huang, A.; Xie, Z. Isolation and characterization of cellulolytic marine bacteria for Litopenaeus Vannamei aquaculture using sugarcane bagasse as carbon source. Research Square 2020, https://doi.org/10.21203/rs.3.rs-67558/v1

63. Yokoe, Y.; Yasumasu, I. The distribution of cellulase in invertebrates. Comp. Biochem.Physiol. 1964, 13, 323-338, https://doi.org/10.1016/0010-406X(64)90027-1.

64. Cazemier, A.E.; den Camp, H.J.; Hackstein, J.H.; Vogels, G.D. Fibre digestion in arthropods. Comp. Biochem.Physiol. 1997, 118, 101-109, https://doi.org/10.1016/S0300-9629(96)00443-4.

65. Pothula, R.; Shirley, D.; Perera, O.P.; Klingeman, W.E.; Oppert, C.; Abdelgaffar, H.M.; Johnson, B.R.; Jurat-Fuentes, J.L. The digestive system in Zygentoma as an insect model for high cellulase activity. PloS one 2019, 14, https://doi.org/10.1371/journal.pone.0212505.

66. Dillon, R.J.; Dillon, V.M. The gut bacteria of insects: nonpathogenic interactions. Annu. Rev. Entomol. 2004, 49, 71-92, https://doi.org/10.1146/annurev.ento.49.061802.123416.

67. Douglas, A.E. Lessons from studying insect symbioses. Cell Host Microbe 2011, 10, 359-367, https://doi.org/10.1016/j.chom.2011.09.001.

68. Willis, J.D.; Oppert, C.; Jurat-Fuentes, J.L. Methods for discovery and characterization of cellulolytic enzymes from insects. Insect Sci. 2010, 17, 184-198, https://doi.org/10.1111/j.1744-7917.2010.01322.x.

69. Brune, A.; Dietrich, C.The gut microbiota of termites: digesting the diversity in the light of ecology and evolution. Апnu. Rev. Microbiol. 2015, 69, 145-166, https://doi.org/10.1146/annurev-micro-092412155715 .

70. Ohkuma, M. Termite symbiotic systems: efficient bio-recycling of lignocellulose.Appl. Microbiol. Biotechnol. 2003, 61, 1-9, https://doi.org/10.1007/s00253-002-1189-z.

71. Scharf, M.E.; Tartar, A. Termite digestomes as sources for novel lignocellulases. Biofuel. Bioprod. Bior. 2008, 2, 540-552, https://doi.org/10.1002/bbb.107.

72. Kumar, A.; Poonia, A.; Sharma, R.; Jangra, M.; Sehrawat, R.; Sansanwal, R. Termite gut: home to microbiome. Uttar Pradesh Journal of Zoology 2020, 41, 9-23.

73. Breznak, J.A.; Brune, A. Role of microorganisms in the digestion of lignocellulose by termites. Annu. Rev. Entomol. 1994, 39, 453-487, https://doi.org/10.1146/annurev.en.39.010194.002321.

74. Upadhyaya, S.K.; Manandhar, A.; Mainali, H.; Pokhrel, A.R.; Rijal, A.; Pradhan, B.; Koirala, B. Isolation and characterization of cellulolytic bacteria from gut of termite. Rentech Symposium Compendium 2012, 1, 14-18.

75. Wenzel, M.; Schönig, I.; Berchtold, M.; Kämpfer, P.; König, H. Aerobic and facultatively anaerobic cellulolytic bacteria from the gut of the termite Zootermopsis angusticollis. J. Appl. Microbiol. 2002, 92, 32-40, https://doi.org/10.1046/j.1365-2672.2002.01502.x.

76. Sibanda, A.; Ruzvidzo, O.; Ncube, I.; Ncube, T. Diversity of cellulase and xylanase-producing filamentous fungi from termite mounds. J. Yeast and Fungal Res. 2019, 10, 1529,https://doi.org/10.5897/JYFR2019.0189.

77. Hethener, P.; Brauman, A.; Garcia, J.L.Clostridium termitidis sp. nov., a cellulolytic bacterium from the gut of the wood-feeding termite, Nasutitermes lujae. Syst. Appl. Microbiol. 1992, 15, 52-58, https://doi.org/10.1016/S0723-2020(11)80138-4. 
78. Ferbiyanto, A.; Rusmana, I.; Raffiudin, R.Characterization and identification of cellulolytic bacteria from gut of worker Macrotermes gilvus. HAYATI J. Biosci. 2015, 22, 197-200, https://doi.org/10.1016/j.hjb.2015.07.001.

79. Tarun, L.J.R.Molecular characterization of cellulose-hydrolyzing bacteria isolates from the gut of Philippine milk termite (Coptotermes gestroi). Asia Pac. J. Res. 2016, 1, 136-143.

80. Peristiwati; Natamihardja, Y.S.; Herlini, H. Isolation and identification of cellulolytic bacteria from termites gut (Cryptotermes sp.). J. Phys. Conf. Ser. 2018, 1013,https://doi.org/10.1088/1742-6596/1013/1/012173.

81. Egwuatu, T.F.; Appeh, O.G. Isolation and characterization of filter paper degrading bacteria from the guts of Coptotermes formosanus. J. Bioremed. Biodegrad. 2018, 9, https://doi.org/10.4172/2155-6199.1000440.

82. Nidhi, K.; Gupta, S.K.; Bura, A.; Gandhi, A. Diversity of cellulose hydrolyzing bacteria from the gut of Coptotermes heimi (Rhinotermitidae). Asian J. Biol. Life Sci. 2018, 7, 28-32.

83. Tsegaye, B.; Balomajumder, C.; Roy, P. Isolation and characterization of novel lignolytic, cellulolytic, and hemicellulolytic bacteria from wood-feeding termite Cryptotermes brevis. Int. Microbiol. 2019, 22, 29-39, https://doi.org/10.1007/s10123-018-0024-Z.

84. Ali, H.R.; Hemeda, N.F.; Abdelaliem, Y.F. Symbiotic cellulolytic bacteria from the gut of the subterranean termite Psammotermes hypostoma Desneux and their role in cellulose digestion. AMB Express 2019, 9, https://doi.org/10.1186/s13568-019-0830-5.

85. Femi-Ola, T.O.; Oyebamiji, B.A. Molecular characterization and cellulolytic activities of bacterial isolates from the hindgut of wood-feeding termites Amitermes evuncifer Silvestri. J. Adv. Microbiol. 2019, 1-10, https://doi.org/10.9734/JAMB/2019/45732.

86. Arfah, R.A.; Natsir, H.; Atifah, N.; Zarkoni, T.R.; Mahmud, M. Isolation and characterization of soil termites (Macrotermes gilvus) cellulolytic bacteria and activity determination of cellulase enzyme on newsprint substrates. J. Phys. Conf. Ser. 2019, 1341, https://doi.org/10.1088/1742-6596/1341/3/032037.

87. Lang, S.S.; Hung, K.J.; Huat, O.K.P.; Samsi, I.H.; Sarbini, S.R.B. Digestive system of worker termite Coptotermes curvignathus Holmgren and its chemical and cellulolytic microbial properties. Serangga 2020 , $25,45-64$.

88. Huang, S.W.; Zhang, H.Y.; Marshall, S.; Jackson, T.A. The scarab gut: a potential bioreactor for bio-fuel production. Insect Sci. 2010, 17, 175-183, https://doi.org/10.1111/j.1744-7917.2010.01320.x.

89. Cazemier, A.E.; Verdoes, J.C.; Reubsaet, F.A.; Hackstein, J.H.; van der Drift, C.; Den Camp, H.J. Promicromonospora pachnodae sp. nov., a member of the (hemi) cellulolytic hindgut flora of larvae of the scarab beetle Pachnoda marginata. Antonie van Leeuwenhoek 2003, 83, 135-148, https://doi.org/10.1023/a:1023325817663.

90. Sheng, P.; Huang, S.; Wang, Q.; Wang, A.; Zhang, H. Isolation, screening, and optimization of the fermentation conditions of highly cellulolytic bacteria from the hindgut of Holotrichia parallela larvae (Coleoptera: Scarabaeidae). Appl. Biochem. Biotechnol. 2012, 167, 270-284, https://doi.org/10.1007/s12010-012-9670-3.

91. Sari, S.L.A.; Pangastuti, A.; Susilowati, A.; Purwoko, T.; Mahajoeno, E.; Hidayat, W.; Mardhena, I.; Kurniawati, D.; Anitasari, R. Cellulolytic and hemicellulolytic bacteria from the gut of Oryctes rhinoceros larvae. Biodiversitas 2016, 17, 78-83.

92. Dini, I.R.; Wawan, W.; Hapsoh, H.; Sriwahyuni, S. Isolation and identification of cellulolytic and lignolytic bacteria from the gut Oryctes rhinoceros L. larvae decomposition of oil palm empty fruit bunches. Indonesian J. Agr. Res. 2018, 1, 193-203, https://doi.org/10.32734/injar.v1i2.314.

93. Shelomi, M.; Chen, M.J. Culturing-enriched metabarcoding analysis of the Oryctes rhinoceros gut microbiome. Insects 2020, 11,https://doi.org/10.3390/insects11110782.

94. Handique, G.; Phukan, A.; Bhattacharyya, B.; Baruah, A.A.; Rahman, S.W.; Baruah, R. Characterization of cellulose degrading bacteria from the larval gut of the white grub beetle Lepidiota mansueta (Coleoptera: Scarabaeidae). Arch. Insect Biochem. Physiol. 2017, 94, https://doi.org/10.1002/arch.21370.

95. Mabhegedhe, M. Cellulolytic activities of the dung beetle, Euoniticellus intermedius, larva gut micro-flora. The Open Biotechnol. J. 2017, 11, 105-113, https://doi.org/10.2174/1874070701711010105.

96. Soko, K.M.; Bhattacharya, R.C.; Ramakrishnan, B.; Sharma, K.; Subramanian, S. Functional characterization of bacteria isolated from different gut compartments of white grub, Anamola dimidiata, larvae. J. Environ. Biol. 2020, 41, 1526-1535, http://doi.org/10.22438/jeb/41/6/MRN-1420.

97. $\mathrm{Hu}, \mathrm{X}$; $\mathrm{Yu}, \mathrm{J}$.; Wang, C.; Chen, H. Cellulolytic bacteria associated with the gut of Dendroctonus armandi larvae (Coleoptera: Curculionidae: Scolytinae). Forests 2014, 5, 455-465, https://doi.org/10.3390/f5030455.

98. Hatefi, A.; Makhdoumi, A.; Asoodeh, A.; Mirshamsi, O. Characterization of a bi-functional cellulase produced by a gut bacterial resident of Rosaceae branch borer Beetle, Osphranteria coerulescens (Coleoptera: Cerambycidae). Int. J. Biol. Macromol. 2017, 103, 158-164, https://doi.org/10.1016/j.ijbiomac.2017.05.042.

99. Bhuvaragavan, S.; Reshma, T.; Hilda, K.; Balaji, R.; Meenakumari, M.; Mathivanan, N.; Janarthanan, S. Purification and characterization of an endogenous cellulase from the digestive system of grub of banana pseudostem weevil Odoiporus longicollis (Olivier). Research Square 2020, https://doi.org/10.21203/rs.3.rs$38095 / \mathrm{v} 1$. 
100. Dantur, K.I.; Enrique, R.; Welin, B.; Castagnaro, A.P. Isolation of cellulolytic bacteria from the intestine of Diatraea saccharalis larvae and evaluation of their capacity to degrade sugarcane biomass. AMB Express 2015, 5, https://doi.org/10.186/s13568-015-0101-z.

101. Barbosa, K.L.; dos Santos Malta, V.R.; Machado, S.S.; Junior, G.A.L.; da Silva, A.P.V.; Almeida, R.M.R.G.; da Luz, J.M.R. Bacterial cellulase from the intestinal tract of the sugarcane borer. Int. J. Biol. Macromol. 2020,161, 441-448,https://doi.org/10.1016/j.ijbiomac.2020.06.042.

102. Anand, A.A.; Vennison, S.J.; Sankar, S.G.; Gilwax Prabhu, D.I.; Vasan, P.T.; Raghuraman, T.; Jerome Geoffrey, C.; Vendan, S.E. Isolation and characterization of bacteria from the gut of Bombyx mori that degrade cellulose, xylan, pectin and starch and their impact on digestion. J. Insect Sci. 2010, 10, https://doi.org/10.1673/031.010.10701.

103. Revathy, K.; Pandiarajan, J. Cellulolytic potential of gut bacterial biomass in silkworm Bombyx mori. L. Ecological Genetics and Genomics 2020, 14, https://doi.org/10.1016/j.egg.2019.100045.

104. Lee, F.J.; Rusch, D.B.; Stewart, F.J.; Mattila, H.R.; Newton, I.L. Saccharide breakdown and fermentation by the honey bee gut microbiome. Environ. Microbiol. 2015, 17, 796-815, https://doi.org/10.1111/14622920.12526.

105. Chakraborty, N.; Sarkar, G.M.; Lahiri, S.C. Cellulose degrading capabilities of cellulolytic bacteria isolated from the intestinal fluids of the silver cricket. Environmentalist 2000, 20, 9-11, https://doi.org/10.1023/A:1006691524607.

106. Banerjee, S.; Maiti, T.K.; Roy, R.N. Production, purification, and characterization of cellulase from Acinetobacter junii GAC 16.2, a novel cellulolytic gut isolate of Gryllotalpa africana, and its effects on cotton fiber and sawdust. Ann. Microbiol. 2020, 70, 1-16, https://doi.org/10.1186/s13213-020-01569-6.

107. Prasad, R.K.; Chatterjee, S.; Mazumder, P.B.; Sharma, S.; Datta, S.; Vairale, M.G.; Dwivedi, S.K. Study on cellulase $(\beta-1,4$-endoglucanase) activity of gut bacteria of Sitophilus oryzae in cellulosic waste biodegradation. Bioresour. Technol. Rep.b 2019, 7, https://doi.org/10.1016/j.biteb.2019.100274.

108. Azizah; Purwatiningsih; Wiyono, H.T.; Muzakhar, K. Morphological and biochemical characteristic of endosymbiont cellulolytic bacteria from gut of Hypothenemus hampei Ferr. and its enzyme activity. In AIP Conference Proceedings 2020, 2296,https://doi.org/10.1063/5.0030576.

109. Nelson, K.; Muge, E.; Wamalwa, B. Cellulolytic Bacillus species isolated from the gut of the desert locust Schistocerca gregaria. Scientific African 2020, 11, https://doi.org/10.1016/j.sciaf.2020.e00665.

110. Yokoe, Y. Cellulase activity in the termite, Leucotermes speratus, with new evidence in support of a cellulase produced by the termite itself. Scientific Papers of the College of General Education, University of Tokyo, Biology 1964, 14, 115-120.

111. Watanabe, H.; Noda, H.; Tokuda, G.; Lo, N. A cellulase gene of termite origin. Nature 1998, 394, 330-331, https://doi.org/10.1038/28527.

112. Lee, S.J.; Kim, S.R.; Yoon, H.J.; Kim, I.; Lee, K.S.; Je, Y.H.; Lee, S.M.; Seo, S.J.; Sohn, H.D.; Jin, B.R. cDNA cloning, expression, and enzymatic activity of a cellulase from the mulberry longicorn beetle, Apriona germari. Comp. Biochem. Physiol. B Biochem. Mol. Biol. 2004, 139, 107-116, https://doi.org/10.1016/j.cbpc.2004.06.015.

113. Wei, Y.D.; Lee, K.S.; Gui, Z.Z.; Yoon, H.J.; Kim, I.; Zhang, G.Z.; Guo, X.; Sohn, H.D.; Jin, B.R. Molecular cloning, expression, and enzymatic activity of a novel endogenous cellulase from the mulberry longicorn beetle, Apriona germari. Comp. Biochem. Physiol. B Biochem. Mol. Biol. 2006, 145, 220-229, https://doi.org/10.1016/j.cbpb.2006.07.007.

114. Kunieda, T.; Fujiyuki, T.; Kucharski, K.R.; Foret, S.S.; Ament, A.; Toth, A.L.; Ohashi, K.; Takeuchi, H.; Kamikouchi, A.; Kage, E.; Morioka, M. Carbohydrate metabolism genes and pathways in insects: insights from the honey bee genome. Insect Mol. Biol. 2006, 15, 563-576, https://doi.org/10.1111/j.13652583.2006.00677.x.

115. Kim, N.; Choo, Y.M.; Lee, K.S.; Hong, S.J.; Seol, K.Y.; Je, Y.H.; Sohn, H.D.; Jin, B.R. Molecular cloning and characterization of a glycosyl hydrolase family 9 cellulase distributed throughout the digestive tract of the cricket Teleogryllus emma. Comp. Biochem. Physiol. B Biochem. Mol. Biol. 2008, 150, 368-376, https://doi.org/10.1016/j.cbpb.2008.04.005.

116. Tokuda, G.; Watanabe, H.; Matsumoto, T.; Noda, H. Cellulose digestion in the wood-eating higher termite, Nasutitermes takasagoensis (Shiraki): distribution of cellulases and properties of endo- $\beta$ - 1 , 4-glucanase. Zool. Sci. 1997, 14, 83-93, https://doi.org/10.2108/zsj.14.83.

117. Warnecke, F.; Luginbuhl, P.; Ivanova, N.; Ghassemian, M.; Richardson, T.H.; Stege, J.T.; Cayouette, M.; Mc Hardy, A.C.; Djordjevic, G.; Aboushadi, N.; Sorke, R. Metagenomic and functional analysis of hindgut microbiota of a wood-feeding higher termite. Nature 2007, 450, 560-565, https://doi.org/10.1038/nature06269.

118. Liu, J.; Song, K.; Teng, H.; Zhang, B.; Li, W.; Xue, H.; Yang, X. Endogenous cellulolytic enzyme systems in the longhorn beetle Mesosa myops (Insecta: Coleoptera) studied by transcriptomic analysis. Acta Biochim. Biophys. Sin. 2015, 47, 741-748, https://doi.org/10.1093/abbs/gmv070.

119. Ferreira, A.H.; Marana, S.R.; Terra, W.R.; Ferreira, C. Purification, molecular cloning, and properties of a $\beta$-glycosidase isolated from midgut lumen of Tenebrio molitor (Coleoptera) larvae. Insect Biochem. Mol. Biol. 2001, 31, 1065-1076, https://doi.org/10.1016/S0965-1748(01)00054-6. 
120. Slaytor, M. Cellulose digestion in termites and cockroaches: what role do symbionts play? Comp. Biochem. Physiol. B Biochem. Mol. Biol. 1992, 103, 775-784, https://doi.org/10.1016/0305-0491(92)90194-V.

121. Willis, J.D.; Klingeman, W.E.; Oppert, C.; Oppert, B.; Jurat-Fuentes, J.L. Characterization of cellulolytic activity from digestive fluids of Dissosteira carolina (Orthoptera: Acrididae). Comp. Biochem. Physiol. B Biochem. Mol. Biol. 2010, 157, 267-272, https://doi.org/10.1016/j.cbpb.2010.06.012.

122. Su, L.J.; Liu, H.; Li, Y.; Zhang, H.F.; Chen, M.; Gao, X.H.; Wang, F.Q.; Song, A.D. Cellulolytic activity and structure of symbiotic bacteria in locust guts. Genet. Mol. Res. 2014, 13, 7926-7936, https://doi.org/10.4238/2014.september.29.6.

123. Beloqui, A.; Nechitaylo, T.Y.; López-Cortés, N.; Ghazi, A.; Guazzaroni, M.E.; Polaina, J.; Strittmatter, A.W.; Reva, O.; Waliczek, A.; Yakimov, M.M.; Golyshina, O.V. Diversity of glycosyl hydrolases from cellulose-depleting communities enriched from casts of two earthworm species. Appl. Environ. Microbiol. 2010, 76, 5934-5946, https://doi.org/10.1128/AEM.00902-10.

124. Shankar, T.; Mariappan, V.; Isaiarasu, L. Screening cellulolytic bacteria from the mid-gut of the popular composting earthworm, Eudrilus eugeniae (Kinberg). World J. Zool. 2011, 6, 142-148.

125. Utekar, G.V.; Deshmukh, H.V.Characterization of Bacillus sp. from gut flora of earthworm Eudrillus eugeniae feed on sugar industry waste. Res. J. Life Sci. Bioinform. Pharm. Chem. Sci. 2019, 5, 887-895, https://doi.org/10.26479/2019.0502.66.

126. Shankar, T.; Sankaralingam, S.; Balachandran, C.; Chinnathambi, A.; Nasif, O.; Ali Alharbi, S.; Park, S.; Baskar, K. Purification and characterization of carboxymethylcellulase from Bacillus pumilus EWBCM1 isolated from earthworm gut (Eudrilus eugeniae). J. King Saud Univ.-Sci. 2020, 33,https://doi.org/10.1016/j.jksus.2020.101261.

127. Fujii, K.; Ikeda, K.; Yoshida, S. Isolation and characterization of aerobic microorganisms with cellulolytic activity in the gut of endogeic earthworms. Int. Microbiol. 2012, 15, 121-130, https://doi.org/10.2436/20.1501.01.165.

128. Jyotsna, K.P.; Vijayalakshmi, K.; Prasanna, N.D.; Shaheen, S.K. Isolation, characterization of cellulase producing Lysinibacillus sphaericus MTCC No. 9468 from gut of Eisenia foetida. Bioscan 2011, 6, 325327.

129. Parihar, D.K. Isolation and screening of cellulolytic bacteria inhabiting gut of Eisenia fetida fed on municipal solid waste. Int. Adv. Res. J. Sci. Eng. Technol. 2016, 3, 84-88.

130. Dey, K.K.; Talukdar, N.C.; Nongkhlaw, F.M.; Thakuria, D. Isolation, characterization and practical significance of cellulose degrading bacteria from the gut wall of two ecologically distinct earthworms. Curr. Sci. 2018, 114 .

131. Zhang, B.G.; Rouland, C.; Lattaud, C.; Lavelle, P. Activity and origin of digestive enzymes in gut of the tropical earthworm Pontoscolex corethrurus. European J. Soil Biol. 1993, 29, 7-11.

132. Lattaud, C.; Locati, S.; Mora, P.; Rouland, C. Origin and activities of glycolytic enzymes in the gut of the tropical geophagous earthworm Millsonia anomala from Lamto (Cỗ te d'Ivoire). Pedobiologia 1997, 41, $242-251$.

133. Lattaud, C.; Zhang, B.G.; Locati, S.; Rouland, C.; Lavelle, P. Activities of the digestive enzymes in the gut and in tissue culture of a tropical geophagous earthworm, Polypheretima elongata (Megascolecidae). Soil Biol. Biochem.1997, 29, 335-339, https://doi.org/10.1016/S0038-0717(96)00021-1.

134. Garvín, M.H.; Lattaud, C.; Trigo, D.; Lavelle, P.Activity of glycolytic enzymes in the gut of Hormogaster elisae (Oligochaeta, Hormogastridae). Soil Biol. Biochem. 2000, 32, 929-934, https://doi.org/10.1016/S0038-0717(99)00222-9.

135. Lattaud, C.; Mora, P.; Garvín, M.H.; Locati, S.; Rouland, C.Enzymatic digestive capabilities in geophagous earthworms-origin and activities of cellulolytic enzymes. Pedobiologia 1999, 43, 842-850.

136. Nozaki, M.; Miura, C.; Tozawa, Y.; Miura, T. The contribution of endogenous cellulase to the cellulose digestion in the gut of earthworm (Pheretima hilgendorfi: Megascolecidae). Soil Biol. Biochem. 2009, 41, 762-769, https://doi.org/10.1016/j.soilbio.2009.01.016.

137. Raut, S.K.; Ghose, K.C. Pestiferous land snail of India. Technical Monograph ZSI, Calcutta 1984, 11.

138. Biedermann, W.; Moritz, P. Beiträge zur vergleichenden physiologie der Verdauung. II. Über ein celluloselösendes enzyme im Lebersekret der Schnecke (Helix pomatia). Pflügers Archiv 1898, 73, 219287, https://doi.org/10.1007/BF01796256.

139. Seilliere, G. Ulitisation des pentosanes par les organismes animaux. C. R. Acad. Sci. Paris 1907, 145, 104143.

140. Florkin, M.; Lozet, F. Origine bacterienne de la cellulase du contenu intestinal de L'Escargot. Arch. Int. Physiol. Biochim. Biophys. 1949, 57, 201-207.

141. Jeuniaux, C. Highlighting of a chitinolytic bacterial flora in the digestive tube of Esgargot ("Helix Pomatia L"). Arch. Int. Physiol. 1950, 58, 350-351, https://doi.org/10.3109/13813455009144965.

142. Jeuniaux, C.The intestinal chitinolytic bacterial flora of the snail (Helix pomatia L.): quantitative and qualitative analysis. Bull. Soc. R. Sci. Liège.1955, 254-270.

143. Soedigdo, R.; Nio, L.S.; Adiwikarta, S.; Barnett, R.C. Cellulase from the snail Achatina fulica (Fer).Physiol. Zool. 1970, 43, 139-144, https://doi.org/10.1086/physzool.43.2.30155523. 
144. Dar, M.A.; Chintalchere, J.M.; Pandit, R.S. Extraction and characterization of endogenous cellulases in Achatina fulica for lignocellulose digestion. Fundam. Appl. Agric. 2020, 5, 224-234, https://doi.org/10.5455/faa.91698.

145. Pinheiro, G.L.; Correa, R.; Soares, R.; Cardoso, A.; Chaia, C.; Clementino, M.M.; Garcia, E.; Souza De, W.; Frasés, S. Isolation of aerobic cultivable cellulolytic bacteria from different regions of the gastrointestinal tract of giant land snail Achatina fulica. Front. Microbiol. 2015, 6,https://doi.org/10.3389/fmicb.2015.00860.

146. Wijanarka, W.; Kusdiyantini, E.; Parman, S.Screening cellulolytic bacteria from the digestive tract of snail (Achatina fulica) and test the ability of cellulase activity. Biosaintifika: J. Biol. Biol. Edu.2016, 8, 385-391, https://doi.org/10.15294/biosaintifika.v8i3.7263.

147. Aravind, K.K.; Sandeep, S.; Subramaniyan, S. Analysis of microbes and their enzymes in Achatina fulica. Int. J. Sci. Res.2017, 6, 1897-1903.

148. Oyeleke, S.B.; Egwim, E.C.; Oyewole, O.A.; John, E.E.Production of cellulase and protease from microorganisms isolated from gut of Archachatina marginata (Giant African Snail). SciTechnol 2012, 2, 15-20, https://doi.org/10.5923/j.scit.20120201.03.

149. Ademolu, K.O.; Ojo, V.O; Bamidele, J.A.B.; Adelabu, A.B.; Ebenso, I.; Idowu, A.B. Feeding pattern and gut enzymes activity of Giant African land snail (Archachatina marginata) during growth phases. Arch. Zootec. 2017, 66, 29-34, https://doi.org/10.21071/az.v66i253.2122.

150. Charrier, M.; Brune, A.The gut microenvironment of helicid snails (Gastropoda: Pulmonata): in-situ profiles of $\mathrm{pH}$, oxygen and hydrogen determined by microsensors. Can. J. Zool. 2003, 81, 928-935, https://doi.org/10.1139/z03-071.

151. Charrier, M.Y.; Fonty, G.; Gaillard-Martini, B.; Ainouche, K.; Andant, G. Isolation and characterization of cultivable fermentative bacteria from the intestine of two edible snails, Helix pomatia and Cornu aspersum (Gastropoda: Pulmonata). Biol. Res. 2006, 39, 669-681,https://doi.org/10.4067/s0716-97602006000500010.

152. Charrier, M.; Combet-Blanc, Y.; Ollivier, B. Bacterial flora in the gut of Helix aspersa (Gastropoda Pulmonata): evidence for a permanent population with a dominant homolactic intestinal bacterium, Enterococcus casseliflavus. Can. J. Microbiol. 1998, 44, 20-27.

153. Gomare, S.; Kim, H.A.; Ha, J.H.; Lee, M.W.; Park, J.M. Isolation of the polysaccharidase-producing bacteria from the gut of sea snail, Batillus cornutus. Korean J. Chem. Eng. 2011, 28, 1252-1259, https://doi.org/10.1007/s11814-010-0506-y.

154. Distel, D. L.; Morril, W.; Maclaren-Toussaint, N.; Franks, D.; Waterbury J. Teredinibacter turnerae gen. nov., sp. nov., a dinitrogen-fixing, cellulolytic, endosymbiotic gamma-proteobacterium isolated from the gills of wood-boring molluscs (Bivalvia: Teredinidae). Int. J. Syst. Evol. Microbiol. 2002, 52, 2261-2269.

155. O’Connor, R.M.; Fung, J.M.; Sharp, K.H.; Benner, J.S.B.; Mc Clung, C.; Cushing, S.; Lamkin, E.R.; Fomenkov, A.I.; Henrissat, B.; Londer, Y.Y.; Scholz, M.B. Gill bacteria enable a novel digestive strategy in a wood-feeding mollusk. Proc. Nat. Acad. Sci. 2014, 111, E5096-E5104, https://doi.org/10.1073/pnas.1413110111.

156. Altamia, M.A.; Shipway J.R.; Stein, D.; Betcher, M.A.; Fung, J.M.; Jospin, G.; Eisen, J.; Haygood, M.G.; Distel, D.L. Teredinibacter waterburyi sp. nov., a marine, cellulolytic endosymbiotic bacterium isolated from the gills of the wood-boring mollusc Bankia setacea (Bivalvia: Teredinidae) and emended description of the genus Teredinibacter. Int. J. Syst. Evol. Microbiol. 2020, 70, 2388-2394, https://doi.org/10.1099/ijsem.0.004049.

157. Maldonado, G.C.; Moura, M.; Skinner, L.F.; AraÚjo, F.V. Evaluation of wood degradation rates by Teredinidae (Mollusca: Bivalvia) in two ecologically distinct areas, and temperature and salinity influences on the cellulolytic activity of associated bacteria. An. Acad. Bras. Ciênc 2020, 92,https://doi.org/10.1590/0001-3765202020180970.

158. Joynson, R.; Swamy, A.; Bou, P.A.; Chapuis, A.; Ferry, N.Characterization of cellulolytic activity in the gut of the terrestrial land slug Arion ater: biochemical identification of targets for intensive study. Comp. Biochem. Physiol. B Biochem. Mol. Biol. 2014, 177, 29-35, https://doi.org/10.1016/j.cbpb.2014.08.003.

159. Tsuji, A.; Tominaga, K.; Nishiyama, N.; Yuasa, K. Comprehensive enzymatic analysis of the cellulolytic system in digestive fluid of the Sea Hare Aplysia kurodai. Efficient glucose release from sea lettuce by synergistic action of $45 \mathrm{kDa}$ endoglucanase and $210 \mathrm{kDa}$ ß-glucosidase. PLoS One 2013, 8, https://doi.org/10.1371/journal.pone.0065418.

160. Yusuf, M.; Penid, N.; Danjumma, B.J.; Sahabi, B.M. Isolation of cellulolytic and methanogenic bacteria from the mid and hind gut of termites (Isoptera). Int. J. Adv. Acad. Res. Sci. Technol. Eng. 2018, 4, 1-13.

161. Gupta, P.; Samant, K.; Sahu, A. Isolation of cellulose-degrading bacteria and determination of their cellulolytic potential. Int. J. Microbiol. 2012, 2012, 1-5, https://dx.doi.org/10.1155/2012/578925.

162. Shil, R.K.; Mojumder, S.M.; Sadida, F.F.; Uddin, M.; Sikdar, D. Isolation and identification of cellulolytic bacteria from the gut of three phytophagus insect species. Brazilian Arch. Biol. Technol. 2014, 57, 927-932, https://dx.doi.org/10.1590/S1516-8913201402620.

163. Kakara, D.; Malothu, R.; Narayana, E.L. Isolation of cellulolytic bacteria from intestine of termites and their utility in saccharification and fermentation of lignocellulosic biomass.Int. J. Eng. Res. Technol. 2020, 9, 298-302. 
164. Biswas, R.; Persad, A.; Bisaria, V.S.Production of cellulolytic enzymes. In: Bioprocessing of renewable resources to commodity bioproducts.Bisaria, V.S.; Kondo, A. (eds). John Wiley \& Sons, New Jersey, 2014; pp. 105-132, https://doi.org/10.1002/9781118845394.ch5.

165. Galante, Y.M.;De Conti, A.; Monteverdi, R.Application of Trichodermaenzymes in textile industry. In: Trichoderma \& Gliocladium-enzymes, biological control and commercial applications.Harman, G.F.; Kubicek, C.P. (eds). Taylor \& Francis, London, 1998, pp. 311-326.

166. Baker, R.A.; Wicker, L. Current and potential applications of enzyme infusion in the food industry. TrendsFood Sci. Technol. 1996, 7, 279-284, https://doi.org/10.1016/0924-2244(96)10030-3.

167. Hamer, R.J.Enzymes in the baking industry. InEnzymes in food processing, Tucker, G.A.; Woods, L.F.J. (eds).Blackie Academic \& Professional, Glasgow, 1991, pp. 168-193, https://doi.org/10.1007/978-1-46152147-1_6.

168. Maat, J.; Roza, M.; Verbakel, J.; Stam, H.; Santos da Silva, M.J.; Bosse, M.; Egmond, M.R.E.; Hagemans, M.L.D.; van Gorcom, R.F.M.; Hessing, J.G.M.; van den Hondel, C.A.M.J.J.; van Rotterdam, C. Xylanases and their applications in bakery. In: Xylans and xylanases, progress in biotechnology. Visser, J.; Beldman, G.; Kusters-van Someren, M.A.; Voragen, A.G.J. (eds). Elsevier, Amsterdam, 1992; pp. 349-360.

169. Gunata, Y.Z.; Bayonove, C.L.; Cordonnier, R.E.; Arnaud, A.; Galzy, P.Hydrolysis of grape monoterpenyl glycosides by Candida molischiana and Candida wickerhamii $\beta$-glucosidases. J. Sci. Food. Agric. 1990, 50, 499-506, https://doi.org/10.1002/jsfa.2740500408.

170. Prasad, D.Y.; Heitmann, J.A.; Joyce, T.W. Enzymatic de-inking of coloured offset newsprint. Nord. PulpPaper Res. J. 1993, 8, 284-286, https://doi.org/10.3183/npprj-1993-08-02-p284-286.

171. Darwesh, O.M.; El-Maraghy, S.H.; Abdel-Rahman, H.M.; Zaghloul, R.A. Improvement of paper wastes conversion to bioethanol using novel cellulose degrading fungal isolate. Fuel 2020, 262,https://doi.org/10.1016/j.fuel.2019.116518.

172. Karthika, A.; Seenivasagan, R.; Kasimani, R.; Babalola, O.O.; Vasanthy, M. Cellulolytic bacteria isolation, screening and optimization of enzyme production from vermicompost of paper cup waste. Waste Management 2020, 116, 58-65, https://doi.org/10.1016/j.wasman.2020.06.036.

173. Ndlovu, T.M.; van Wyk, J.P.H. Isolation of cellulase enzyme from brown garden snail (Cornu aspersum) for the saccharification of waste paper materials. MethodsX 2019, 6, 1030-1035, https://doi.org/10.1016/j.mex.2019.04.019. 